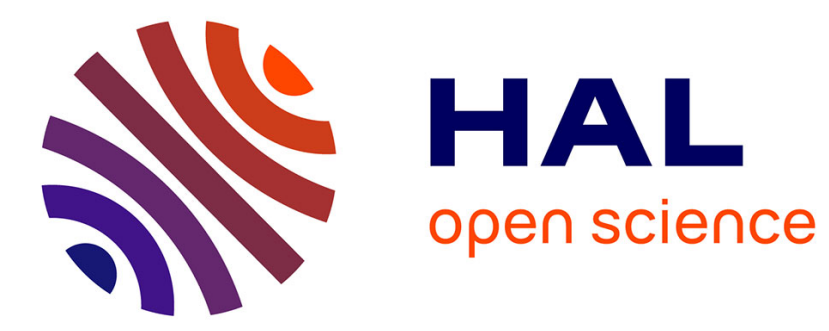

\title{
Generalised cutting force model including contact radius effect for turning operations on Ti6Al4V titanium alloy
}

Théo Dorlin, Guillaume Fromentin, Jean-Philippe Costes

\section{To cite this version:}

Théo Dorlin, Guillaume Fromentin, Jean-Philippe Costes. Generalised cutting force model including contact radius effect for turning operations on Ti6Al4V titanium alloy. International Journal of Advanced Manufacturing Technology, 2016, 86 (9), pp.3297-3313. 10.1007/s00170-016-8422-x . hal01371042

\section{HAL Id: hal-01371042 \\ https://hal.science/hal-01371042}

Submitted on 23 Sep 2016

HAL is a multi-disciplinary open access archive for the deposit and dissemination of scientific research documents, whether they are published or not. The documents may come from teaching and research institutions in France or abroad, or from public or private research centers.
L'archive ouverte pluridisciplinaire HAL, est destinée au dépôt et à la diffusion de documents scientifiques de niveau recherche, publiés ou non, émanant des établissements d'enseignement et de recherche français ou étrangers, des laboratoires publics ou privés. 


\title{
Generalised cutting force model including contact radius effect for turning operations on Ti6Al4V titanium alloy
}

\author{
Théo Dorlin $^{1,2}$ • Guillaume Fromentin ${ }^{1}$ J Jean-Philippe Costes ${ }^{1}$
}

\begin{abstract}
Current constraints on aeronautical parts have led to the introduction of materials like titanium alloys as well as new part geometries featuring large dimensions and reduced thickness. Inappropriate cutting forces during turning operations could lead to high deflections and damage to the machine. In order to ensure the respect of final part geometry and the optimal use of resources, cutting forces have to be known, to anticipate the deformed shape during and after machining operations on thin parts. Current models are offering a solution which can be optimised by the modelling influence of the ploughing effect on cutting forces. Therefore, a mechanistic model is developed in order to improve the prediction of cutting forces during turning operations on titanium alloy Ti6A14V: this model includes the effect of the clearance face contact radius and comprises two main steps. First, the effect of the clearance contact radius and the effect of the cutting edge lead angle are determined independently, via a direct identification method based on elementary cutting tests. Secondly, this analysis is extended to cutting trials in boring, cylindrical turning and face turning. Then, based on a mechanistic approach, a model is defined according to the previous results and the coefficients are identified thanks to cutting trials in real conditions. The results of the proposed model are then compared to a commonly used model which takes into account mostly the uncut chip thickness effect. It is
\end{abstract}

Théo Dorlin

theo.dorlin@ensam.eu

1 Arts et Metiers, ParisTech, LaBoMaP, Rue Porte De Paris, Cluny 71250 , France

2 Safran Tech, Research \& Technology Center, Magny-les-Hameaux 78772, France demonstrated that the proposed cutting force model provides a more accurate prediction of cutting forces.

Keywords Turning $\cdot$ Cutting forces $\cdot$ Predictive model . Contact radius $\cdot$ Cutting edge lead angle $\cdot$ Titanium alloy

\section{Introduction}

In order to meet current energy challenges in terms of reducing oil consumption and pollution levels, aeronautical parts are subjected to new expectations. In order to produce fuelefficient aircraft, materials such as titanium alloys and optimised part geometries have appeared to reduce onboard weight. However, these requirements can give rise to technological difficulties. Indeed, titanium alloys are considered as "difficult-to-cut" materials, due to the conservation of their mechanical properties even at high temperature $[1,2]$. Similarly, most of these geometries are very complex, which can lead in some cases to highly flexible parts. In these critical cases, unsuitable cutting parameters in finishing operations can lead to inappropriate cutting forces, which generate high deflections on the manufactured parts, leading to a loss of quality. These considerations must also be taken into account in the case of roughing operations. In fact, unsuitable cutting parameters in roughing operations could lead to high cutting forces, damaging the part or the machine tool spindle if the workpiece clamping or the machine tool spindle is not adapted. Despite these concerns, manufacturers need to guarantee the respect of the dimensional and geometrical specifications associated with their final parts, whilst optimising the manufacturing process. For this reason, they seek to simulate machining operations precisely, to avoid industrialisation problems as far as possible before manufacturing the first part. Consequently, cutting forces have to be known as 
representative data of the machining operation. On the one hand, cutting forces can be measured during cutting processes, but this leads to costly trials. On the other hand, predictive models, based on a small number of cutting trials, have been developed to predict cutting forces. However, current cutting force models do not seem to be optimised and the aim of this study is to enhance the modelling of cutting forces by taking new parameters into account. A particular attention is given to axial and radial components (i.e. $F_{f}$ and $F_{p}$ ), which are linked to part deflections. Indeed, the industrial application of this research work is the contour turning of a turbojet drum, which is a part with large dimensions, thin thickness and, consequently, a low stiffness.

The metal cutting process had been studied for decades. The main principle, highlighted by Merchant [3] in the case of a continuous chip, consists of chip formation consequent to the shearing of the material induced by the movement of a cutting tool. This analysis was continued by Astakhov [4] in the cases of ductile and fragile materials and expanded by Sun et al. [5] and Sutter and List [6] in the case of Ti6Al4V titanium alloy. According to Albrecht [7], this phenomenon has been identified in multiple cases as the dominant one regarding its contribution to cutting forces. This is why several cutting force models have focused only on this aspect. First, using an empirical approach, Kienzle [8] computed cutting forces generated by the cutting process as a product of a cross-section area and a specific energy coefficient. This formulation was completed by Günay et al. [9] in order to take into account the effects of the rake angle, cutting speed, tool wear and material properties. Meanwhile, from a mechanistic point of view, Armarego [10-12] suggested a local cutting force model related to the uncut chip thickness. This model was completed by Reddy et al. [13, 14], who took into account the influences of the rake angle, the cutting speed and the uncut chip thickness in the case of turning operations. The added value of this model is the introduction of equivalent parameters representative of the variation in each parameter considered along the cutting edge. Although these models provided a good correlation between the modelled cutting forces and the cutting forces measured experimentally in multiple cases, Albrecht [7] indicated that these models are not valid in the case of finishing operations. Huang and Liang [15] made the same observation by comparing the cutting forces measured in finishing operations and the cutting forces modelled considering only the forces induced by chip formation. This gap between the prediction and the measurement is due to the non-linearity correlation between the uncut chip thickness and the cutting forces, according to $\mathrm{Ng}$ et al. [16] and Wyen and Wegener [17]. Zorev [18] suggested that in the case of a non-built-up edge, the cutting tool is in contact with the machined material not only along the rake face but also along the clearance surface. This proposal was echoed by Albrecht [7], who introduced the notion of "parasitic forces" which are representative of the elastic reaction of the layer of machined material lying under the tool. These forces are known to be generally small in comparison with the forces on the rake face, but they can be large and sometimes even exceed the rake face forces, especially in finishing operations.

Therefore, many scientists focused their research work on determining the true value of these cutting forces. First, Albrecht [7] suggested the method of extrapolating the force relationship to a zero depth of cut or uncut chip thickness. However, this method is discussed by Stevenson [19, 20] and Guo [21], who underlined that it did not take into consideration the influence of the uncut chip thickness based on observations from cutting, indentation and compression tests. In parallel, Zorev [18] presented four additional methods, based on cutting configurations, to determine experimentally the forces acting on the clearance face. Popov and Dugin [22, 23] compared the results provided by different methods and developed a new method based on the measurement of the real rear contact between the cutting tool and the material. Based on these studies, cutting force models including the "ploughing effect" were developed. First Zorev [18] proposed, using a mechanical approach, a formulation of the normal force to the clearance face based on the shear stress of the surface layer of the material being machined. This suggestion was enhanced and simplified by Waldorf [24], who also defined the force tangential to the clearance face. From a mechanistic point of view, with respect to Albrecht's conclusions, Armarego [10] introduced the parasitic force as a constant in cutting force models. While in accordance with the observations underlining the correlation of the ploughing forces with the uncut chip thickness and the cutting speed [19-23], Huang and Liang [15] formulated the ploughing forces as a polynomial function of the uncut chip thickness and Kaymacki et al. [25] expressed the ploughing forces as a polynomial function of the cutting speed. Although advances in the field are significant, it seems that the modelling of ploughing forces, and thus the modelling of cutting forces, can be improved.

Indeed, most of the studies concerning the determination or modelling of ploughing forces are performed in planing configuration, or at least within the same part diameter or the same tool diameter. Furthermore, in these studies tool wear is not considered as a factor in the experimental design. However, these two points are not representative of target applications like the contour turning of a Ti6Al4V titanium alloy turbojet drum, which presents large variations in part radius and where tool wear evolution is observed during machining operations. This is why, based on current models, the influence of these two parameters is neglected. Consequently, cutting forces modelled using this approach may be inappropriate and then lead to part deflections during machining. Campocasso et al. [26] support this assessment by highlighting the influence of the part radius on cutting forces in the cylindrical turning of pure copper $\mathrm{Cu}-\mathrm{OFE}$ with an unworn round insert. This 
influence is also observed by Dorlin et al. [27], in the case of Ti6Al4V titanium alloy turning with a worn round insert, who compared the cutting forces gathered from cylindrical turning and face turning tests. Considering that the contact conditions between the machined part and the cutting tool may have a significant influence on cutting forces, the effect of this influence has to be determined and included in future modelling. This point is particularly significant in the practical application of this study due to the large evolution of the part radius along the contour of a turbojet drum. Consequently, the contact between the cutting tool and the machined part is variable and could lead to cutting force variations.

This research work therefore deals with the analysis of the contact radius effect on cutting forces and on the ploughing phenomenon. First, the notion of clearance face contact radius is introduced, to represent the contact conditions at the workpiece-tool interface, in the cases of cylindrical turning, face turning and boring. Secondly, a local analysis of the influence of contact radius on cutting forces is developed using basic cutting configurations. Nevertheless, as pointed out by Campocasso et al. [26], the contact radius and the cutting edge lead angle $\kappa_{r}$ are geometrically associated. This may be the reason why earlier studies developed by Venkatesh et al. [28], Saglam et al. [29] or Khettabi et al. [30] had difficulties in concluding about the effect of the cutting edge lead angle $\kappa_{r}$ on cutting forces. Consequently, the influence of the cutting edge lead angle $\kappa_{r}$ and the effect of contact radius on cutting forces have to be investigated separately. The study of the contact radius effect on cutting forces is then extended in the case of cylindrical turning, face turning and boring, where contact conditions are very different. Based on these observations, a cutting force model including the influence of the contact radius is modelled considering a mechanistic approach. Finally, thanks to an inverse identification methodology, coefficients of the proposed model are identified for a wide range of cutting parameters considering different turning operations. The prediction performed with the proposed model is compared with the cutting forces identified via the commonly used model defined by Armarego [10].

\section{Experimental details}

Cutting tests were performed on a two-axis Numerical Control lathe equipped with analogue outputs. The complete tests were carried out at a cutting speed $V_{c}$ equal to $90 \mathrm{~m} / \mathrm{min}$. This value was determined with respect to tool material pair method defined by the NF E66-520-4 standard [31]. Cutting parameters from the $\mathrm{NC}$ (cutting speed $V_{c}$, feed rate $f$ and tool position on the $\vec{X}_{M}$ and $\vec{Z}_{M}$ axes) were monitored during all the cutting tests, thanks to the analogue outputs, in order to ensure the good conduct of trials and facilitate the analysis post-trials. The machined work material was a Ti6Al4V titanium alloy, and workpiece homogeneity was verified by micro-hardness tests from the heart of the workpiece to the surface. The material was machined using Blaser Blasocut 2000 CF coolant, at low pressure.

Two uncoated carbide cutting tools were used in this study. The local cutting geometries were identical $\left(\alpha_{n}=7^{\circ} ; \gamma_{n}=7^{\circ}\right.$; $\lambda_{s}=0^{\circ}$ ). A 213202 ARNO ProfilCut linear cutting edge insert $\left(r_{\beta} \approx 5 \mu \mathrm{m}\right)$, was used to perform direct identification tests, including orthogonal trials. Indeed, the straight cutting edge of this tool enables the modelling of a segment of the discretised cutting edge. A LCGR1705-500-RP Seco Tools MDT round insert ( $r_{\beta} \approx 18 \mu \mathrm{m} ; r_{\varepsilon}=2.5 \mathrm{~mm}$ ), a common tool for profiling operations in industry, was used in this study for cylindrical turning, face turning and boring cutting trials. The edge radius on the straight inserts was measured thanks to a Surfascan profilometer, while the edge radius on round inserts was quantified using an Alicona dynamic focusing microscope and EdgeMaster software. Tool wear on both cutting tools was examined under a Keyence VHX-1000 optical microscope according to the protocol defined by the ISO 3685 standard [32]. Finally, the cutting force data was acquired, in three directions, with a 9121 Kistler piezoelectric dynamometer and a 5019A Kistler amplifier (Fig. 1).

\section{Geometrical analysis of the interaction between the cutting tool and the workpiece}

As indicated by many researchers during finish turning operations using the tool nose, modelled with a round insert, many
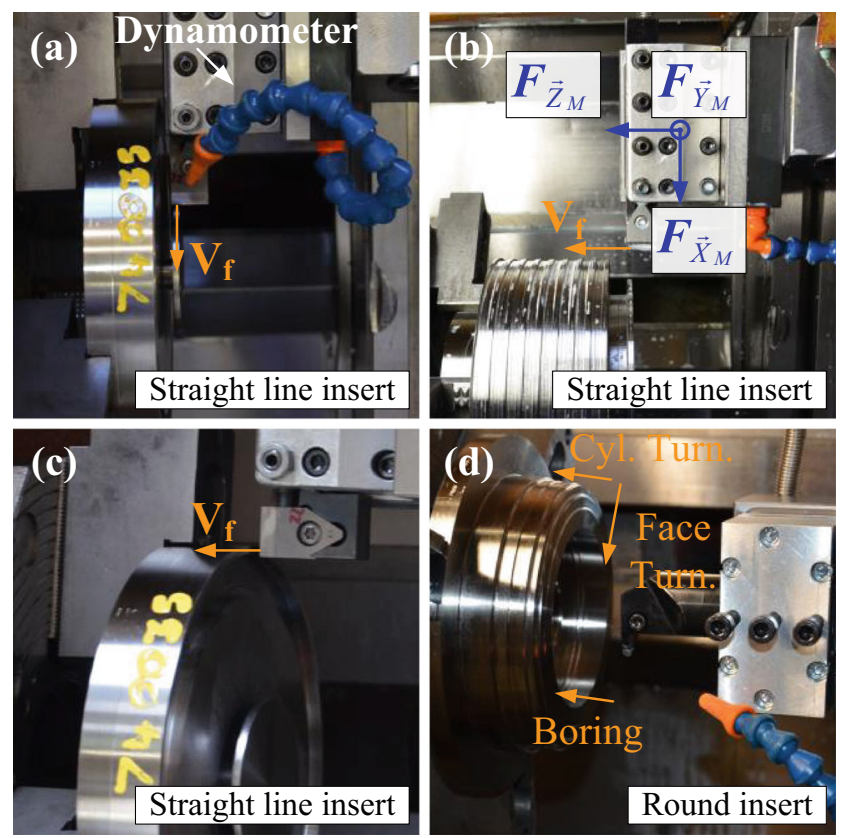

Fig. 1 Experimental setup for cutting tests of a disk (a), a thread (b), a tube (c) and cylindrical turning, face turning and boring cutting trials (d) 
parameters are not constant along the cutting edge. This is the case of the uncut chip thickness [15,33], the cutting edge lead angle $\kappa_{r}$ and the clearance face contact radius as proposed by Campocasso et al. [26] and illustrated by Dorlin et al. [27] in Fig. 2 for cylindrical turning and face turning. The clearance face contact radius, seen in the orthogonal plane defined by the ISO 3002-1 standard [34], corresponds to the distance between the considered point and the revolution axis of the workpiece in the direction of the normal to the tangent to the cutting edge at the considered point. This parameter varies significantly along the cutting edge. Indeed, at point (i), representative of an operation with the depth of cut equal to the corner radius, the $R_{c, c}{ }^{o}$ radius has an infinite value, whereas at point (ii), representative of the point that generates the finished surface, the $R_{c, c}{ }^{o}$ radius is equal to the machined part radius (Fig. 2).

However, this definition can be completed. In fact, as illustrated at (ii) in Fig. 2, in cylindrical turning the $R_{c, c}{ }^{o}$ radius is exclusively convex. In face turning from external to internal, the clearance face contact radius is almost exclusively convex. Nonetheless, the $R_{c, c}{ }^{o}$ radius could be of a different type; for instance, in boring operations, as presented in Fig. 3, the clearance face contact radius is concave. This is also the case in a small portion of the cutting edge in face turning from external
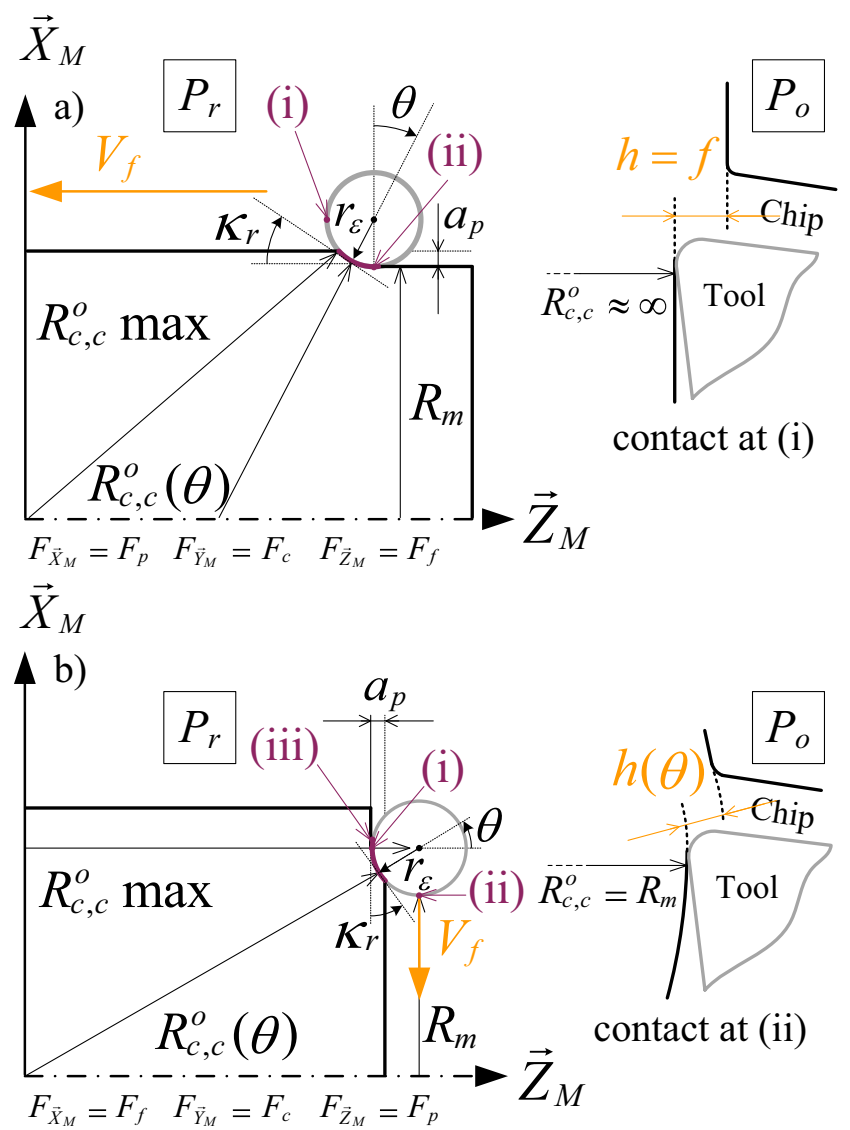

Fig. 2 Schematisation of the $R_{c, c}{ }^{o}$ convex clearance face contact radius in a cylindrical turning and (b) face turning [27]

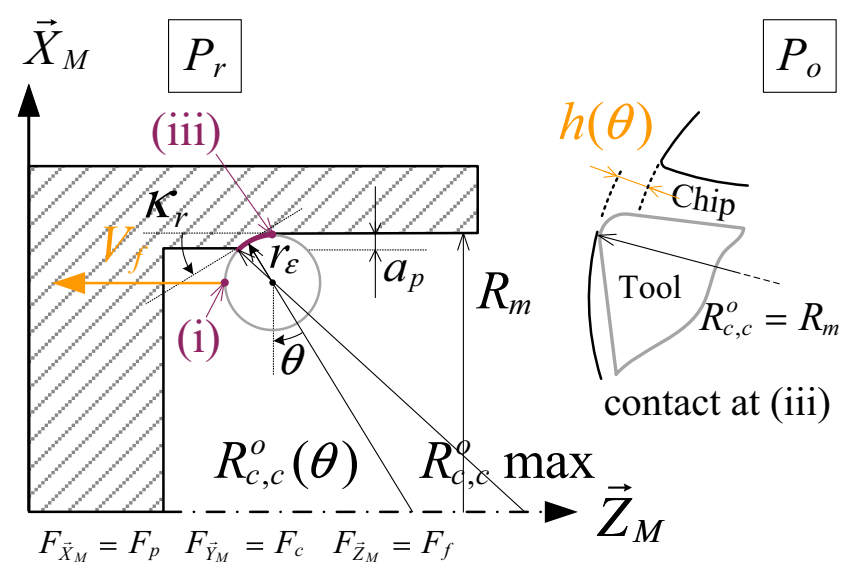

Fig. 3 Schematisation of the $R_{c, c}{ }^{o}$ concave clearance face contact radius in boring

to internal: the crests induced by the passage of the tool lead to a concave $R_{c, c}{ }^{o}$ radius on a small part of the cutting edge (i.e. when $\theta<0^{\circ}$ ), while the rest of the cutting edge in a face turning operation presents a convex $R_{c, c}{ }^{o}$ radius. This last observation will be reversed in the case of face turning from internal to external.

The expressions of clearance face contact radius in turning are defined by the following equations: (1) for cylindrical turning; (2) for convex $R_{c, c}{ }^{o}$ in face turning; (3) for concave $R_{c, c}{ }^{o}$ in face turning and (4) for boring operations.

$$
\begin{array}{ll}
R_{c, c}^{o}=r_{\varepsilon} \times\left(\frac{1}{\cos (\theta)}-1\right)+\frac{R_{m}}{\cos (\theta)} & \forall \theta \\
R_{c, c}^{o}=r_{\varepsilon} \times\left(\frac{1}{\sin (\theta)}-1\right)+\frac{R_{m}}{\sin (\theta)} & \theta>0 \\
R_{c, c}^{o}=r_{\varepsilon} \times\left(\frac{1}{\sin (\theta)}+1\right)+\frac{R_{m}}{\sin (\theta)} & \theta<0 \\
R_{c, c}^{o}=r_{\varepsilon} \times\left(1-\frac{1}{\cos (\theta)}\right)+\frac{R_{m}}{\cos (\theta)} & \forall \theta
\end{array}
$$

To compare the variation in the local parameters ( $\kappa_{r}$ angle, $h$ uncut chip thickness and $R_{c, c}{ }^{o}$ radius in cylindrical turning) along a cutting edge, three graphs are plotted for a given set of cutting parameters and presented in Fig. 4a-c. As illustrated, the radius varies greatly, which is the reason why the influence of this parameter on cutting forces should be analysed. However, as expressed via Eqs. (1), (2), (3) and (4), the variation radius in $R_{c, c}{ }^{o}$ is geometrically associated with the variation in cutting edge lead angle $\kappa_{r}$. Therefore, to study the effect of radius $R_{c, c}{ }^{o}$ on cutting forces, its influence has to be determined independently of the potential influence of cutting edge lead angle $\kappa_{r}$. Sections 4 and 5 are devoted to a local analysis respectively of the cutting edge lead angle effect and the influence of the contact radius on cutting forces. In addition, as illustrated in Fig. $4 \mathrm{~d}-\mathrm{f}$, the variations in radius $R_{c, c}{ }^{o}$ with respect to $h$ uncut chip thickness are not identical 

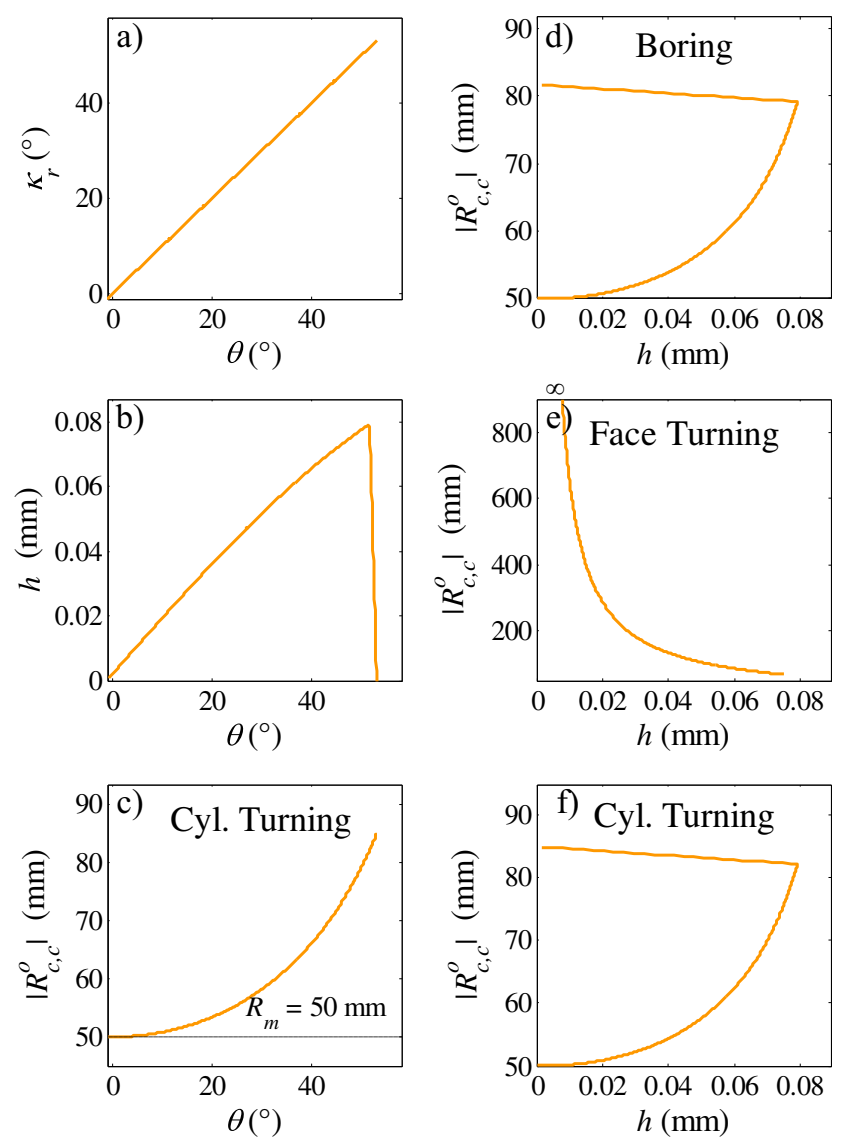

Fig. 4 Variations, with respect to angle $\theta$, in angle $\kappa_{r}(\mathbf{a}), h$ uncut chip thickness (b), $R_{c, c}{ }^{o}$ radius in cylindrical turning (c) and variations, with respect to the $h$ uncut chip thickness, in $R_{c, c}{ }^{o}$ radius in boring (d), face turning (e) and cylindrical turning (f), $\left(R_{m}=100 \mathrm{~mm} ; f=0.1 \mathrm{~mm} / \mathrm{rev}\right.$; $\left.a_{p}=1 \mathrm{~mm}\right)$

between turning operations; for example, for a same $R_{c, c}{ }^{o}$ radius value in cylindrical turning and face turning, the $h$ uncut chip thickness values are not the same. At the global scale, this observation enables us to separate the $h$ uncut chip thickness and $R_{c, c}{ }^{o}$ radius effects.

\section{Local analysis of the cutting edge lead angle effect on cutting forces}

\subsection{Cutting tests on a disk and a threaded workpiece}

The aim of this section is to quantify the effect of angle $\kappa_{r}$ on cutting forces. As a consequence, the first difficulty lies in finding experimental configurations which suggest several levels of angle $\kappa_{r}$ while maintaining other potentially influential parameters constant. Therefore, two cutting configurations, using the straight tool, were used and are illustrated in Fig. 5: first, the cutting of a threaded workpiece, which enables an experimental test to be performed with the cutting edge parallel to the feed direction (i.e. $\kappa_{r}=0^{\circ}$ ). Secondly, this

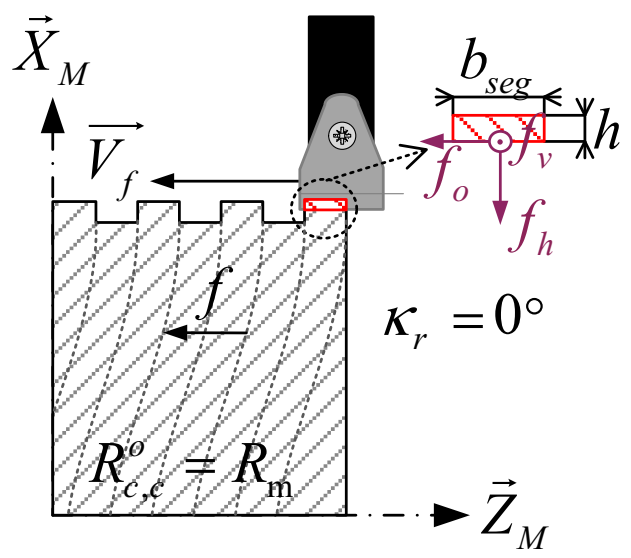

(a) cutting of a thread

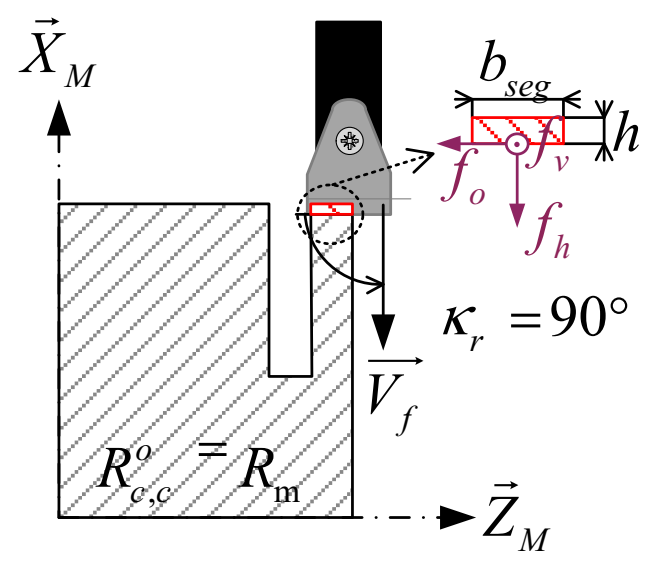

(b) orthogonal cutting of a disk

Fig. 5 Schematics of cutting edge lead angle experimental configurations. (a) Cutting of a threaded workpiece; (b) orthogonal cutting of a disk

configuration can be compared to the orthogonal cutting of a disk, in which the only difference is the value of angle $\kappa_{r}$ To ensure the non-influence of radius $R_{c, c}{ }^{o}$ on cutting force acquisition, both tests were performed on the same workpiece radius.

The scientific community has also highlighted a strong interaction between flank wear and cutting forces [35, 36]. Therefore, this influence was taken into account in the experimental design in several ways. First, to limit the influence of flank wear on the variation in cutting forces during the acquisition, each trial was performed over a short cutting length corresponding to five revolutions (i.e. one revolution for the tool engagement, three revolutions in steady-state conditions and one revolution for the tool exit). Secondly, to limit the influence of flank wear between trials, the number of trials was reduced as much as possible in order to allow a comparison between trials. However, in order to ensure measurement repeatability, each trial was repeated. The experimental plan comprises two experimental tests conducted twice with the same 
titanium Ti6Al4V workpiece and the same insert to limit dispersions. The cutting force measurement results are presented in Fig. 6.

\subsection{Results and observations}

The first observation to be made is that despite the high pitch of the thread, which leads to a high speed tangential to the cutting edge, the $f_{o}$ component of the local cutting force is negligible compared with the two other components $f_{v}$ and $f_{h}$. This is why it is relevant to consider the threaded workpiece cutting test as an elementary cutting plan model with only two components. Thus, the cutting force values presented are not corrupted by the appearance of a third component, and the comparison of cutting force intensities between the two cutting configurations is possible.

As shown in Fig. 6, the second observation is that cutting forces $f_{v}$ and $f_{h}$ rise slightly when angle $\kappa_{r}$ increases from $0^{\circ}$ to $90^{\circ}$. This influence seems to be identical for the $f_{v}$ and $f_{h}$ components, both of which increase by approximately $3 \%$. Nevertheless, the increase is small with respect to the range of variation in angle $\kappa_{r}$ Although the $f_{o}$ component is negligible, its decrease is significant and is linked to the feed rate increase. Indeed, the $V_{f}$ feed rate is 45 times higher in the threaded workpiece cutting test than in the orthogonal cutting of a disk, as mentioned in Fig. 6.

According to these observations, since the sensitivity of cutting forces with respect to the angle is extremely low compared to the influence of other parameters (e.g. the effect of the uncut chip thickness [37]), this parameter is considered as negligible on the cutting forces. Thus, it will not be included in the formulation of the new model.

\section{Local analysis of the influence of contact radius on cutting forces in orthogonal cutting}

\subsection{Cutting tests on disks and on tubes}

Since the influence of the angle on cutting forces is explained separately from the potential $R_{c, c}{ }^{o}$ radius effect, the aim of this section is to quantify the influence of this radius on cutting forces. Similarly to the approach adopted to determine the effect of angle $\kappa_{r}$ on cutting forces, experimental cutting configurations should be adapted in order to observe cutting force variations depending only on the variation in radius $R_{c, c}{ }^{o}$.

Two orthogonal cutting configurations were chosen to quantify the effect of radius $R_{c, c}{ }^{o}$ on cutting forces: the orthogonal cutting of a disk, described earlier in Sect. 4.1, and the orthogonal cutting of a tube, as illustrated in Fig. 7. This latter configuration allowed us, with respect to the definition presented in Fig. 2, to reach an infinite value for radius $R_{c, c}{ }^{o}$ while maintaining cutting tool lead angle $\kappa_{r}$ at $90^{\circ}$.

The experiments were performed with the same Ti6Al4V workpiece and with the same insert. To consider the influence of flank wear on cutting forces, the experimental procedure was divided into three levels of flank wear $V_{B} \in\{0 ; 0.05 ; 0.1\}$ $\mathrm{mm}$. The usual $V_{B}$ limit is about $0.3 \mathrm{~mm}$, so these levels are acceptable in production. Again, cutting trials were carried out over a short cutting length, corresponding to five revolutions, and repeated. The number of cuts was also limited as much as
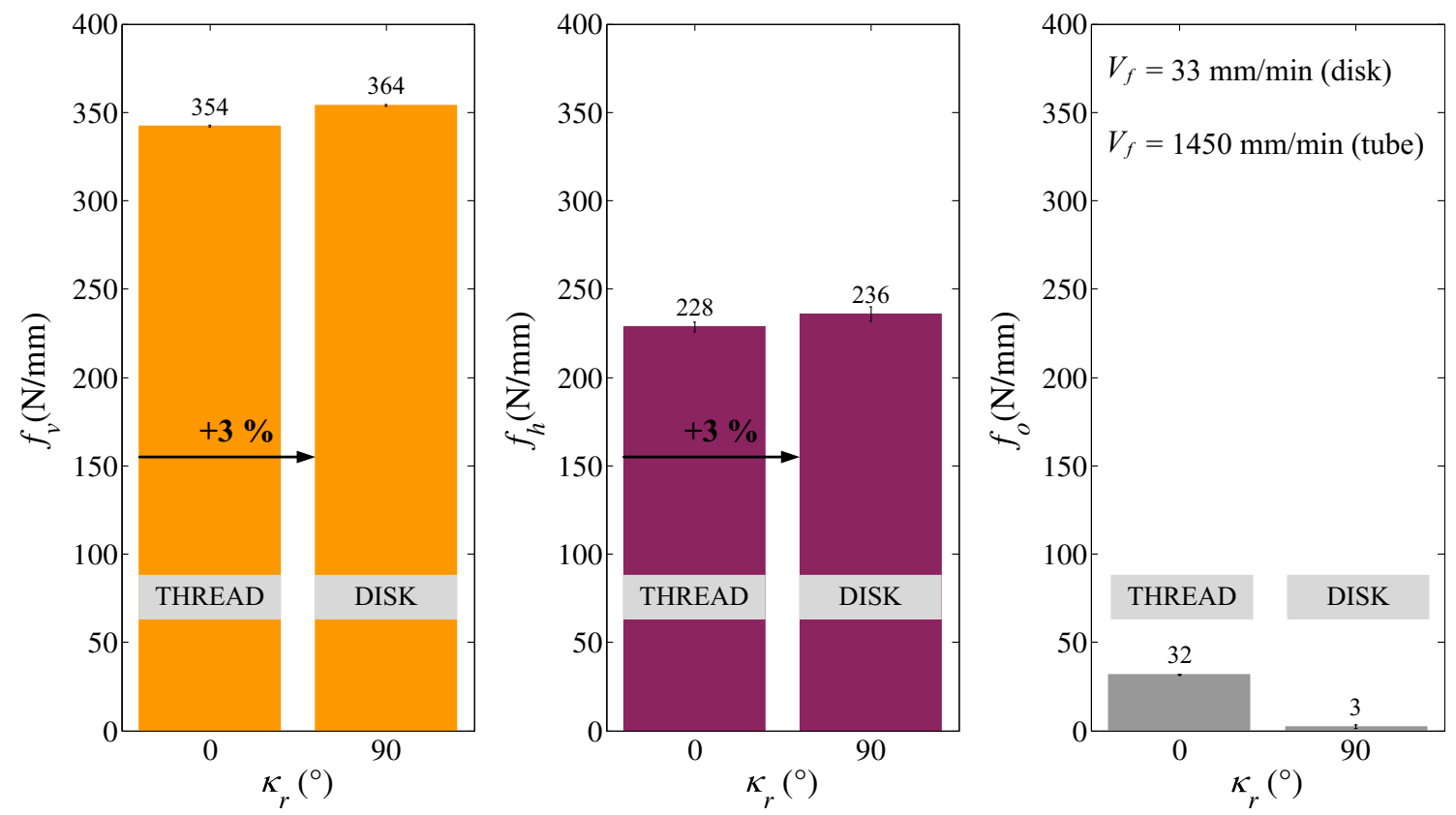

Fig. 6 Cutting force variation on a thread and on a disk with respect to angle $\kappa_{r}$ variation $\left(h=0.2 \mathrm{~mm} ; b_{s e g}=3 \mathrm{~mm} ; f_{v}=F_{c} / b_{s e g} ; f_{h}=F_{p} / b_{s e g} ; f_{o}=F_{f} / b_{s e g}\right)$ 


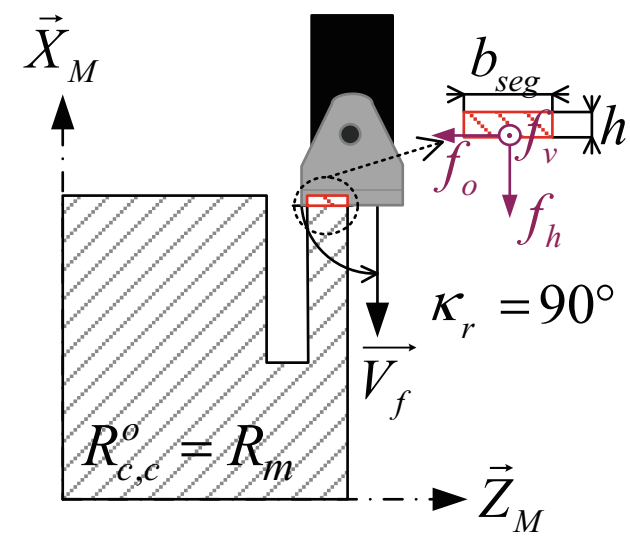

(a) orthogonal cutting of a disk

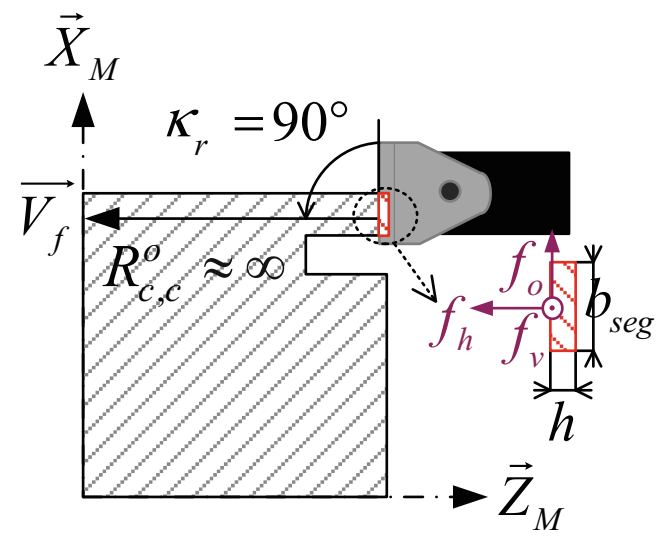

(b) orthogonal cutting of a tube

Fig. 7 Schematics of clearance face contact radius experimental configurations. (a) Orthogonal cutting of a disk; (b) orthogonal cutting of a tube possible. The results of these measurements are shown in Fig. 8.

\subsection{Results and observations}

Firstly, the clearance face contact radius does not have a significant effect on cutting forces in the first two cases of flank wear. Indeed, although there is a slight gap between the $f_{h}$ component ascertained in disk and tube configurations for a new cutting edge (i.e. $V_{B}=0 \mu \mathrm{m}$ ), the cutting force intensity is small. Therefore, a small difference in cutting force could lead to a high percentage of variation.

Nevertheless, in the third case of flank wear, $V_{B}=100 \mu \mathrm{m}$, the effect of radius $R_{c, c}{ }^{o}$ clearly appears: the cutting forces rise with the increase in radius $R_{c, c}{ }^{o}$. The increase is about $15 \%$ and is identical on both components. In this case, the influence of radius $R_{c, c}{ }^{o}$ on the cutting forces is significant. Consequently, it seems that flank wear and radius $R_{c, c}{ }^{o}$ have a coupled effect on cutting forces.

\subsection{Physical investigation of radius effect}

The results presented in Fig. 8 highlight a coupled effect of radius $R_{c, c}{ }^{o}$ and flank wear on cutting forces. It suggests that the origin of these cutting force variations is associated to a phenomenon in the flank face of the cutting tool. However, to have a more precise idea of the initiating phenomena, chips were collected from each test and were observed. The aim of this examination was to determine if the variation in radius $R_{c}$, ${ }_{c}^{o}$ leads to changes in chip formation.
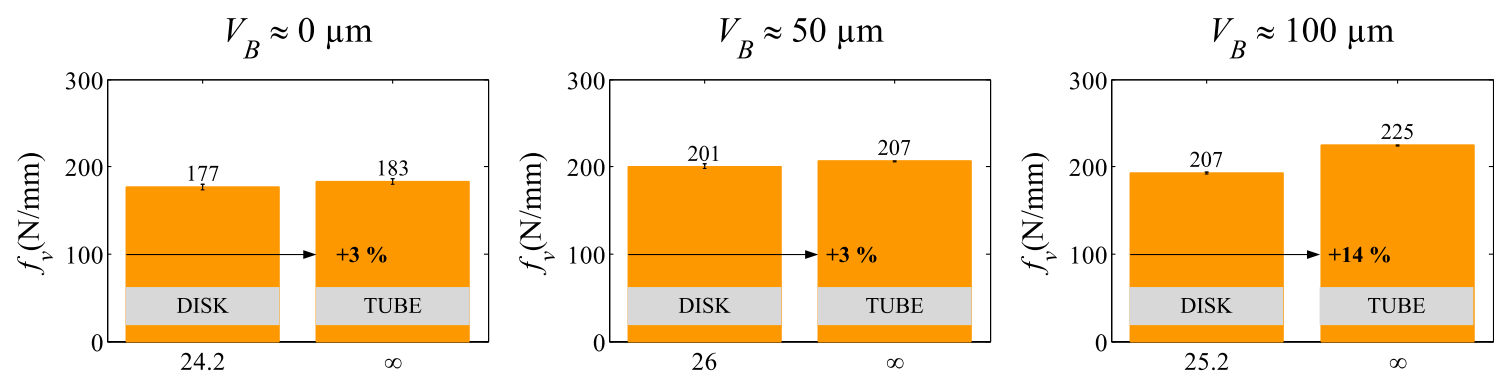

$1000 \mu \mathrm{m}$
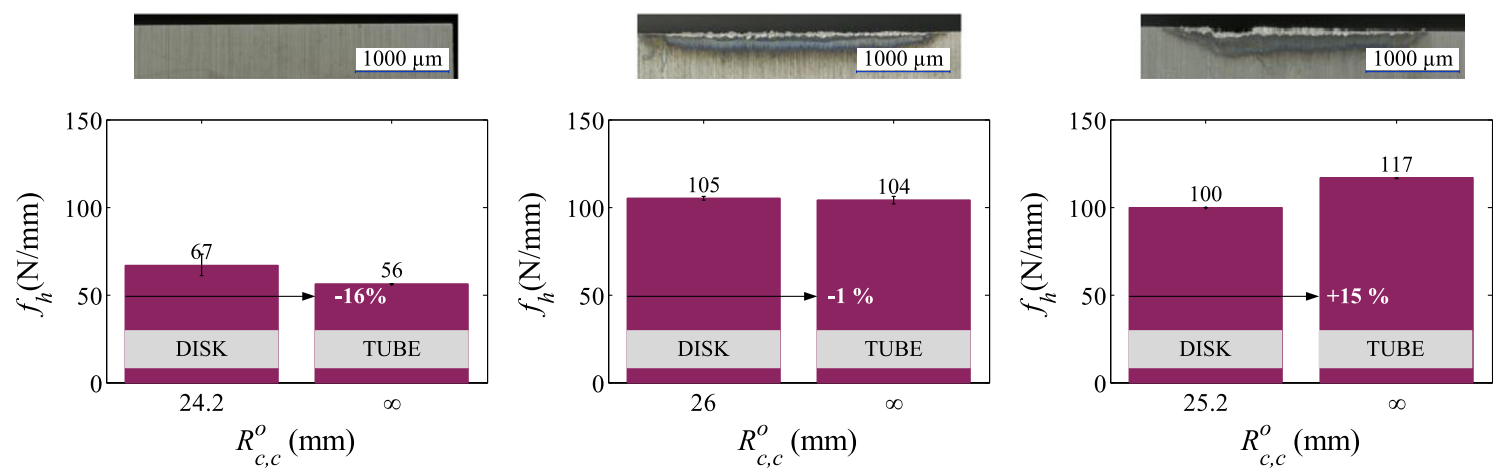

Fig. 8 Cutting force variations on a disk and on a tube with respect to variation in radius $\left(h=0.1 \mathrm{~mm} ; b=3 \mathrm{~mm} ; K_{r}=90^{\circ} ; f_{v}=F_{c} / b_{s e g} ; f_{h}=F_{p} / b_{s e g}\right)$ 

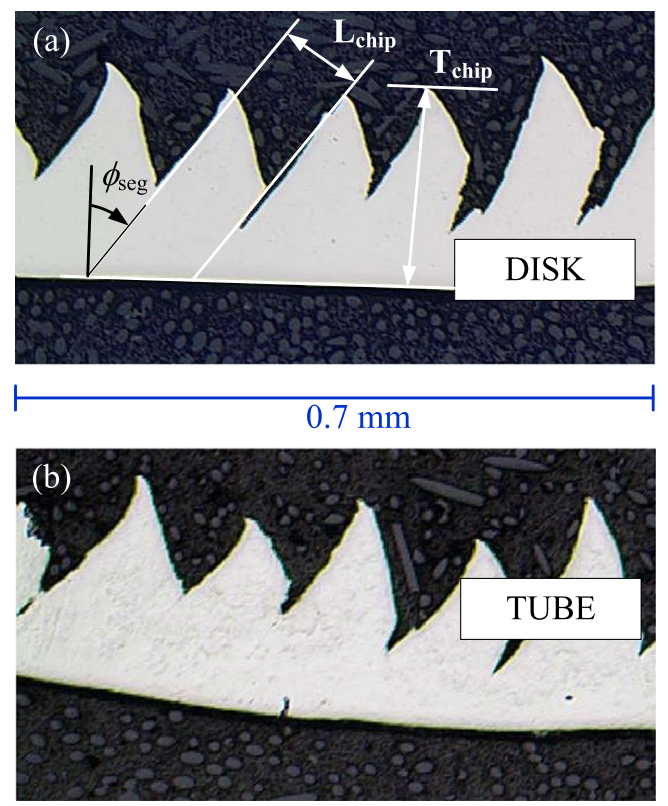

Fig. 9 Chip microphotographs obtained for disk (a) and tube (b)

To ensure good conditions for optical examination, the chips were mounted into bakelite, polished and then observed using an optical microscope. The evaluation was based on two major criteria, the shearing angle and the segmentation frequency, in accordance with Sutter and List [6]. The analysis was repeated for 10 serrated chips in order to reach a trustworthy measured value. Chip microphotographs are shown in Fig. 9, and a quantitative analysis is presented in Table 1.

The observations show slight differences between the different configurations. However, a large part of these variations is probably attributable to repeatability issues. The radius effect observed on cutting forces seems to not find its origin in the chip formation. Therefore, the hypothesis made is that the radius effect observed on cutting forces is linked to the contact conditions between the flank face ploughing and the generated surface. The identification of this parameter as the clearance face contact radius in the orthogonal plane is now justified.

Physically, this increase in cutting forces associated with a larger $R_{c, c}{ }^{o}$ radius could be interpreted in two ways. From a geometrical point of view, with the hypothesis of a constant

Table 1 Measurement from chip examination at different radius $R_{c, c}{ }^{o}$ values $\left(V_{c}=90 \mathrm{~m} / \mathrm{min} ; h=0.2 \mathrm{~mm} ; b=3 \mathrm{~mm}\right)$

\begin{tabular}{llllll}
\hline $\begin{array}{l}R_{c, c}^{o} \text { avg. } \\
(\mathrm{mm})\end{array}$ & $\begin{array}{l}\phi_{\text {seg }} \\
\left({ }^{\circ}\right)\end{array}$ & $\begin{array}{l}L_{\text {chip }} \text { avg. } \\
(\mathrm{mm})\end{array}$ & $\begin{array}{l}T_{\text {chip }} \text { avg. } \\
(\mathrm{mm})\end{array}$ & $\begin{array}{l}V_{\text {chip }} \\
(\mathrm{m} / \mathrm{min})\end{array}$ & $\begin{array}{l}F_{\text {chip }} \\
(\mathrm{kHz})\end{array}$ \\
\hline 24 & 37.4 & 0.13 & 0.23 & 77 & 9.6 \\
95.8 & 37.3 & 0.15 & 0.24 & 74 & 8.3 \\
95.5 & 37 & 0.15 & 0.25 & 73 & 7.9 \\
$\infty$ & 39 & 0.15 & 0.26 & 70 & 7.7 \\
$\infty$ & 37.8 & 0.13 & 0.21 & 86 & 10.9 \\
\hline
\end{tabular}

pressure at the interface, a longer contact between the flank face of the cutting tool and the machined surface could lead to higher cutting force amplitudes, as illustrated in Fig. 10. From a mechanical point of view, a deeper contact due to a modification of the separation point [38] could lead to a higher pressure at the interface and thus to higher cutting forces for the same contact length between the flank face and the generated surface.

In conclusion, based on the local analysis, the influence of the clearance face contact radius is definitely significant, and this parameter will thus be included in the formulation of the new cutting force model.

\section{Global analysis of the influence of contact radius on cutting forces in contour turning}

\subsection{Cutting tests in cylindrical turning, face turning and boring configurations}

As presented in Sect. 5, at the local scale, the radius shows a significant effect on cutting forces. To extend this analysis to concave radius cases, cutting trials were carried out in cylindrical turning, face turning and boring with the round insert, as illustrated in Figs. 2 and 3. As the uncut chip thickness and the clearance face contact radius vary along the cutting edge, cutting trials were performed for a single and small depth of cut value. Indeed, maintaining a low value for the depth of cut allows us to dissociate the clearance face contact radius variation ranges between each cutting configuration. Therefore, a comparison of cutting force magnitudes

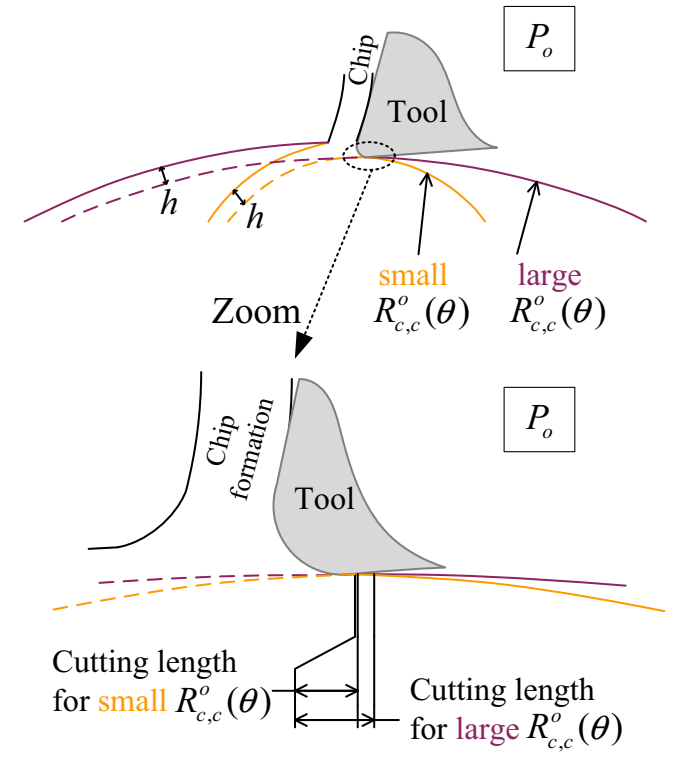

Fig. 10 Illustration of the different contacts between the flank face and the generated surface with respect to radius $R_{c, c}{ }^{o}$ 
Table 2 Experimental parameters for cutting tests used to evaluate the $R_{c, c}{ }^{o}$ radius effect in the global approach

\begin{tabular}{lllllll}
\hline Trial number & Type $f$ & $\begin{array}{l}a_{p} \\
(\mathrm{~mm} / \mathrm{r})\end{array}$ & $\begin{array}{l}\left|R_{c, c}{ }^{o} \max \right| \\
(\mathrm{mm})\end{array}$ & $\begin{array}{l}\left|R_{c, c}{ }^{o} \min \right| \\
(\mathrm{mm})\end{array}$ & $\begin{array}{l}2 * R_{m} \\
(\mathrm{~mm})\end{array}$ \\
\hline 1 & B. & 0.1 & 0.5 & 49 & 40 & 80 \\
2 & F. & 0.1 & 0.5 & $+\infty$ & 105 & 124 \\
3 & C. & 0.1 & 0.5 & 94 & 71 & 141 \\
4 & B. & 0.175 & 0.5 & 49 & 40 & 80 \\
5 & F. & 0.175 & 0.5 & $+\infty$ & 104 & 123 \\
6 & C. & 0.175 & 0.5 & 94 & 71 & 141 \\
7 & B. & 0.25 & 0.5 & 49 & 40 & 80 \\
8 & F. & 0.25 & 0.5 & $+\infty$ & 102 & 121 \\
9 & C. & 0.25 & 0.5 & 94 & 71 & 141 \\
\hline
\end{tabular}

$B$. boring, $C$. cylindrical turning, $F$. face turning

between the three cutting configurations in these conditions leads to the direct observation of the clearance face contact radius effect at the global scale. Based on the conclusions in Sect. 5, flank wear was included in the experimental design for a single value, $V_{B}=100 \mu \mathrm{m}$. Finally, cutting tests were developed for three feed rates to reach different values for uncut chip thickness and to analyse the coupled effect between radius $R_{c, c}{ }^{o}$ and the uncut chip thickness. Analogously, the number of trials was limited as much as possible, and each cutting trial was performed over a short cutting length equivalent to five revolutions. The experimental plan is detailed in Table 2, and results are presented in Fig. 11.

\subsection{Results and observations}

The first observation is that the tendencies observed are identical, regardless of the feed variations. Therefore, the following observations are valid for any feed rate.

Secondly, in accordance with observations at the local scale in Sect. 5, the cutting forces measured in face turning are always superior to those measured in cylindrical turning. This means that the cutting forces increase when the convex $R_{c, c}{ }^{o}$ increases. The $F_{p}$ and $F_{f}$ components are the most sensitive, with an average increase respectively of 12 and $21 \%$, while the $F_{c}$ component presents a slight average increase of $4 \%$. Those results are in accordance with Dorlin et al. [27] observations.

Thirdly, a concave $R_{c, c}{ }^{o}$ radius, provided by the boring configuration, generates higher cutting forces for each component than those measured for the face turning configuration. Between these two configurations, the $F_{c}$ and $F_{p}$ components grow by $13 \%$ and the $F_{f}$ increases by $18 \%$. This observation matches the geometrical analysis in Sect. 5.3, which presents a longer contact between the flank face of the cutting tool and the generated surface with a concave radius than with a convex radius.

Finally, the global analysis with the round insert is in agreement with the local analysis with the straight insert: the analysis shows that the contact radius has a significant effect on cutting forces. Moreover, as expected from a geometrical point of view, a concave contact radius seems to lead to an even more substantial increase in cutting forces than a convex contact radius does.
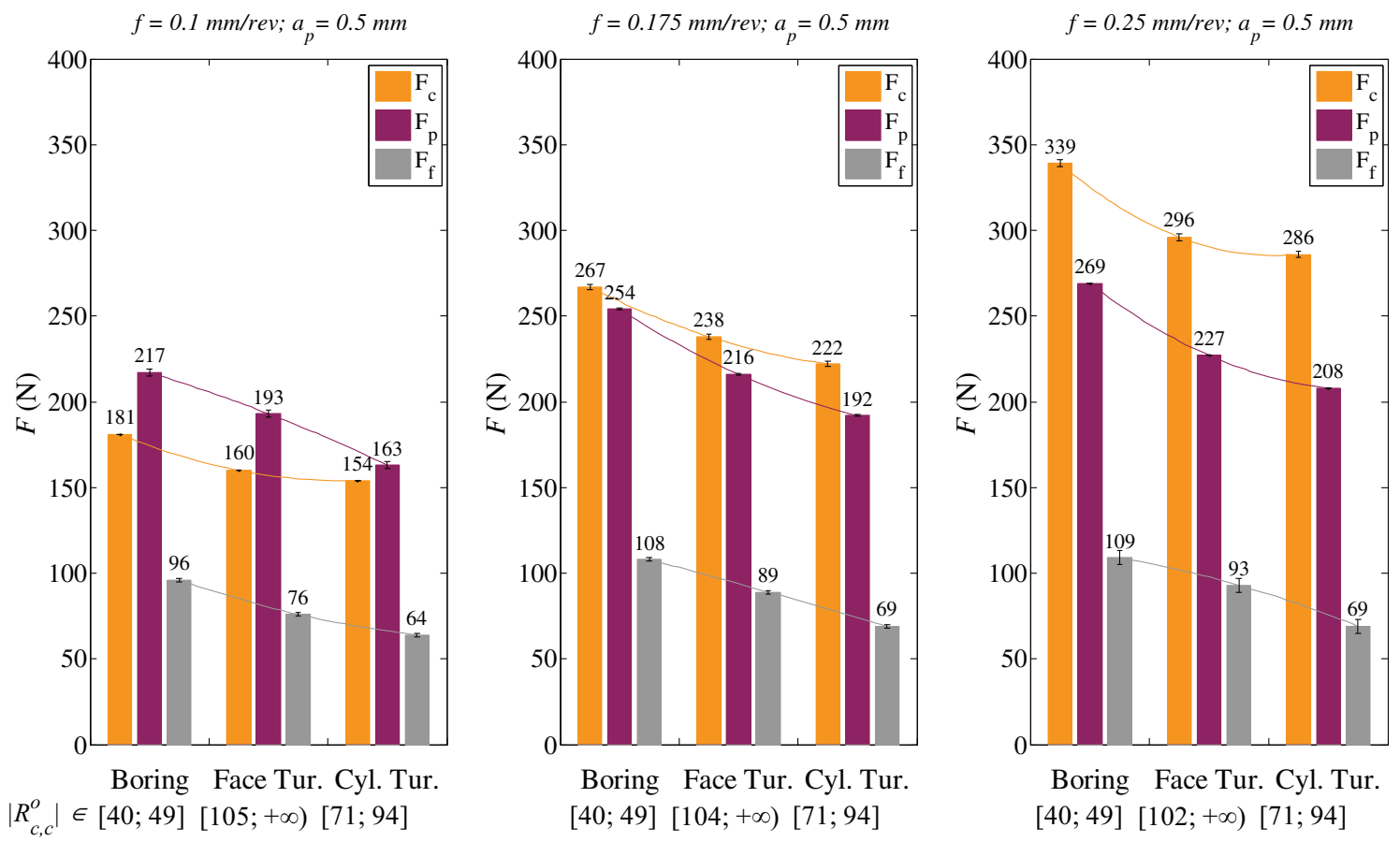

Fig. 11 Global cutting force variations in cylindrical turning, face turning and boring with respect to radius $R_{c, c}{ }^{o}$ variations $\left(V_{B}=100 \mu \mathrm{m}\right)$ 
Fig. 12 Edge discretisation concept illustrated in the case of cylindrical turning with a round insert [26]

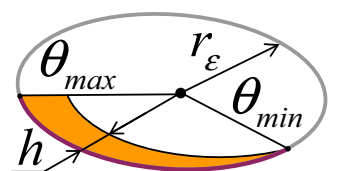

Active edge

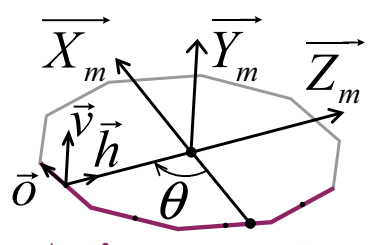

Active segments

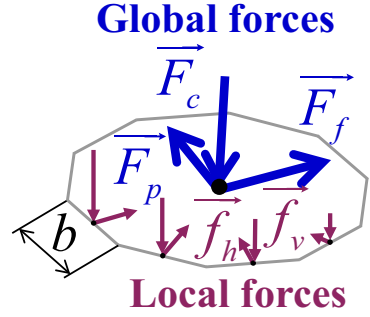

Based on the observations from the global analysis of the influence of radius on cutting forces, this parameter will be included in the formulation of a new cutting force model.

\section{Cutting force modelling: application to cylindrical turning, face turning and boring}

\subsection{Methodologies and principles used}

In order to model cutting forces, the discretisation concept is employed. As presented by Armarego and Epp [10], Kaymakci et al. [25], Campocasso et al. [26, 33] or Lin et al. [39], the concept consists of discretising a complex cutting edge into small segments. It is initially assumed that each segment is considered independent from the others because the round insert presents a large tool nose radius.

Next, geometrical and cutting parameters are associated with each segment. In this research work, geometrical parameters like clearance face contact radius (Eqs. (1)-(4)) and uncut chip thickness are calculated analytically [15, 33]. Furthermore, the uncut chip thickness in the small triangular part of the cross-section area is calculated for small depth of cut values. Indeed, in the literature, this part is often neglected in finishing operations, whereas it could only be negligible for large depth of cut values. It is even less negligible when the insert has a large tool nose radius, which is the case in this study.

In order to express the global cutting force model, local cutting forces modelled are projected and summed, as expressed by Eqs. (5), (6) and (7) in the case of a cutting edge with no obliquity:

$F_{c}=\sum_{j=1}^{N b_{\text {seg }}} f_{v, j}$

$F_{p}=\sum_{j=1}^{N b_{s e g}} f_{h, j} \times \cos \left(\theta_{j}\right)$

$F_{f}=\sum_{i=1}^{N b_{s e g}} f_{h, j} \times \sin \left(\theta_{j}\right)$

Finally, to determine the values of unknown coefficients, an inverse identification methodology is used thanks to a developed algorithm based on the minimisation of a least squares problem and the Levenberg-Marquardt method, as illustrated in Fig. 13. Moreover, the effect of the number of discretised segments has been analysed in order to find a value which presents small calculation time and robust results.
Fig. 13 Cutting force simulation and inverse identification algorithm approach in turning

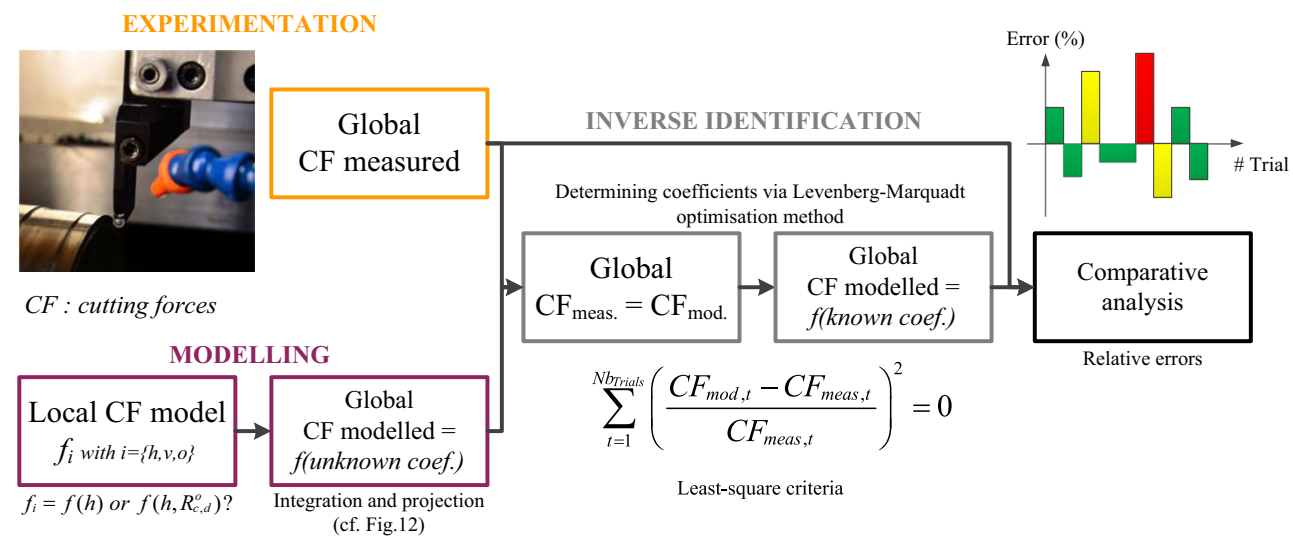




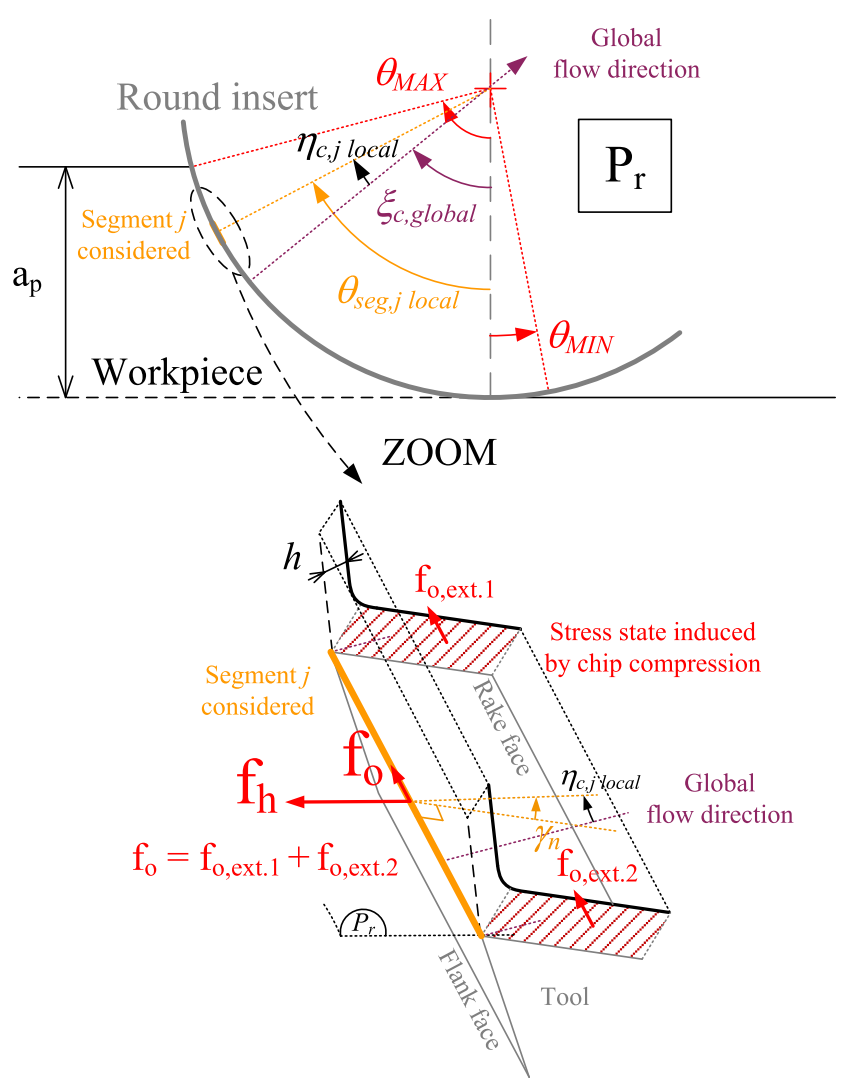

Fig. 14 Geometric model for definition of the third local component

Therefore, the number of segments of the discretised cutting edge is fixed to 500 .

\subsection{Formulation of the new predictive model}

The scientific literature points to a linear correlation between uncut chip thickness and cutting forces [37]. Based on this observation and on a mechanistic approach, Armarego [10]

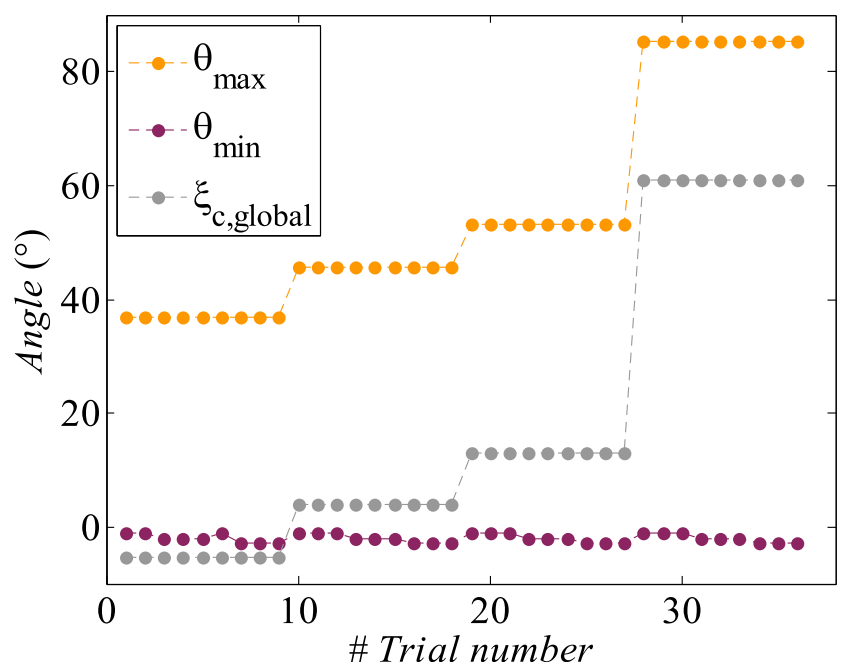

Fig. 15 Chip global flow direction model evolution (9 and 13) with experimental trials (cf. Eqs. (9) and (10))
Table 3 Details for residual degree of freedom calculation in case of predictive model

\begin{tabular}{llll} 
& & $f_{h}$ & $f_{v}$ \\
\hline Nb. Unknown & $n_{\text {unk }}$ & 4 & 4 \\
Nb. Trials & $n_{e q}$ & 36 & 72 \\
Res. DOF & $n_{\text {eq }}-n_{\text {unk }}$ & 32 & 68 \\
\hline
\end{tabular}

suggested a cutting force model with two local components (cf. Fig. 12) composed of constants $\left(k_{i X}\right)$ and parameters related to the considered segment $\left(h_{j}\right)$, which is considered as a reference and detailed in Eq. (8). Therefore, in order to evaluate the accuracy obtained with the proposed models, the relative errors of modelling between the measured cutting forces and the predicted cutting forces, using the proposed models then the Armarego's model, are compared.

$$
f_{i, j}=\left(\begin{array}{c}
k_{i 0}+\underbrace{k_{i 1} \times h_{j}}_{\text {edge effect }}
\end{array}\right) \times b_{\text {seg }}
$$

with $i \in\{h, v\}$

As observed earlier in Sect. 4, the influence of cutting edge lead angle $\kappa_{r}$ on cutting forces is considered negligible, while based on observations from Sects. 5 and 6 the effect of radius $R_{c, c}{ }^{o}$ is significant. The cutting forces rise with an increase in radius $R_{c, c}{ }^{o}$ and converge to a finite value for an infinite radius $R_{c, c}{ }^{o}$ value. Furthermore, they are more sensitive to this influence for a concave contact radius. Moreover, a convention is established: a convex contact radius is considered as negative, while a concave contact radius is chosen as positive. Therefore, according to those observations, a new cutting force model with two local components was elaborated via a mechanistic approach. In this study, a mechanistic approach has been retained rather than a physical approach due to the complexity to model the edge radius effect via a numerical approach.

The novelty of this model lies in the formulation of the "edge effect", as suggested by investigations in Sect. 5.3, by introducing radius $R_{c, c}{ }^{o}$ under an exponential formulation in order to satisfy previous observations. The edge effect is then associated to the "cut effect" by an additive formulation in order to dissociate the contribution of the primary and second shear zones from the third shear zone and thus provide physical meaning. The proposed model is presented in Eq. (9):

$$
f_{i, j}=(\underbrace{1+e^{\left(\frac{k_{i 3}}{R_{c, c}^{\circ}}\right)}}_{\text {edge effect }}+\underbrace{k_{i 1} \times h_{j}}_{\text {cutting effect }}) \times b_{\text {seg }}
$$


To determine the value of the unknown coefficients, several cutting trials must be performed to provide for the inverse identification method. As the most restrictive suggested model presents only four unknown coefficients, the 36 cutting trials, presented in Table 4 , are sufficient to determine the values of the unknown coefficients without any validation tests thanks to a high residual degree of freedom as explained in Table 3. Moreover, they have been carefully chosen to cover large ranges of uncut chip thickness and clearance face contact radius.

Thanks to the algorithm applicable to cylindrical turning, face turning and boring configurations, the unknown coefficients of the previous models were determined, as explained in Fig. 13. All values are presented in Table 5.

Table 4 Experimental parameters for cutting tests used to evaluate the $R_{c, c}{ }^{o}$ radius effect in the global approach

\begin{tabular}{|c|c|c|c|c|c|c|c|c|c|}
\hline \multirow[t]{2}{*}{ Trial number } & \multirow[t]{2}{*}{ Type } & \multirow{2}{*}{$\begin{array}{l}f \\
(\mathrm{~mm} / \mathrm{r})\end{array}$} & \multirow{2}{*}{$\begin{array}{l}a_{p} \\
(\mathrm{~mm})\end{array}$} & \multirow{2}{*}{$\begin{array}{l}\left|R_{c, c}^{o} \max \right| \\
(\mathrm{mm})\end{array}$} & \multirow{2}{*}{$\begin{array}{l}\left|R_{c, c}^{o} \min \right| \\
(\mathrm{mm})\end{array}$} & \multirow{2}{*}{$\begin{array}{l}2 * R_{m} \\
(\mathrm{~mm})\end{array}$} & \multicolumn{3}{|c|}{ Cutting forces $(\mathrm{N})$} \\
\hline & & & & & & & $\overrightarrow{F_{X}}$ & $\overrightarrow{F_{Y}}$ & $\overrightarrow{F_{Z}}$ \\
\hline 1 & B. & 0.1 & 0.5 & 49 & 40 & 80 & 217 & 181 & 96 \\
\hline 2 & F. & 0.1 & 0.5 & $+\infty$ & 105 & 124 & 76 & 160 & 193 \\
\hline 3 & C. & 0.1 & 0.5 & 94 & 71 & 141 & 163 & 154 & 64 \\
\hline 4 & B. & 0.175 & 0.5 & 49 & 40 & 80 & 254 & 267 & 108 \\
\hline 5 & F. & 0.175 & 0.5 & $+\infty$ & 104 & 123 & 89 & 238 & 216 \\
\hline 6 & $\mathrm{C}$. & 0.175 & 0.5 & 94 & 71 & 141 & 192 & 222 & 69 \\
\hline 7 & B. & 0.25 & 0.5 & 49 & 40 & 80 & 269 & 339 & 109 \\
\hline 8 & F. & 0.25 & 0.5 & $+\infty$ & 102 & 121 & 93 & 296 & 227 \\
\hline 9 & C. & 0.25 & 0.5 & 94 & 71 & 141 & 208 & 286 & 69 \\
\hline 10 & B. & 0.1 & 0.75 & 70 & 50 & 100 & 227 & 196 & 105 \\
\hline 11 & F. & 0.1 & 0.75 & $+\infty$ & 81 & 114 & 118 & 228 & 240 \\
\hline 12 & C. & 0.1 & 0.75 & 103 & 68 & 136 & 195 & 209 & 92 \\
\hline 13 & B. & 0.175 & 0.75 & 70 & 50 & 100 & 264 & 290 & 117 \\
\hline 14 & F. & 0.175 & 0.75 & $+\infty$ & 80 & 113 & 132 & 331 & 256 \\
\hline 15 & C. & 0.175 & 0.75 & 103 & 68 & 136 & 232 & 306 & 102 \\
\hline 16 & B. & 0.25 & 0.75 & 70 & 50 & 100 & 288 & 386 & 128 \\
\hline 17 & F. & 0.25 & 0.75 & $+\infty$ & 79 & 111 & 140 & 421 & 271 \\
\hline 18 & C. & 0.25 & 0.75 & 103 & 68 & 136 & 249 & 381 & 106 \\
\hline 19 & B. & 0.1 & 1 & 80 & 49 & 98 & 269 & 252 & 157 \\
\hline 20 & F. & 0.1 & 1 & $+\infty$ & 81 & 128 & 160 & 278 & 272 \\
\hline 21 & C. & 0.1 & 1 & 120 & 68 & 136 & 234 & 266 & 126 \\
\hline 22 & B. & 0.175 & 1 & 80 & 49 & 98 & 309 & 373 & 164 \\
\hline 23 & F. & 0.175 & 1 & $+\infty$ & 80 & 127 & 169 & 406 & 290 \\
\hline 24 & C. & 0.175 & 1 & 120 & 68 & 136 & 271 & 389 & 138 \\
\hline 25 & B. & 0.25 & 1 & 80 & 49 & 98 & 342 & 482 & 182 \\
\hline 26 & F. & 0.25 & 1 & $+\infty$ & 79 & 125 & 192 & 533 & 309 \\
\hline 27 & C. & 0.25 & 1 & 120 & 68 & 136 & 299 & 477 & 151 \\
\hline 28 & B. & 0.1 & 2.3 & 477 & 41 & 81 & 375 & 480 & 339 \\
\hline 29 & F. & 0.1 & 2.3 & $+\infty$ & 68 & 135 & 343 & 567 & 329 \\
\hline 30 & C. & 0.1 & 2.3 & 917 & 71 & 141 & 294 & 542 & 332 \\
\hline 31 & B. & 0.175 & 2.3 & $+\infty$ & 41 & 81 & 413 & 688 & 353 \\
\hline 32 & F. & 0.175 & 2.3 & 477 & 67 & 134 & 383 & 824 & 364 \\
\hline 33 & C. & 0.175 & 2.3 & $+\infty$ & 71 & 141 & 375 & 822 & 363 \\
\hline 34 & B. & 0.25 & 2.3 & 917 & 41 & 81 & 452 & 881 & 386 \\
\hline 35 & F. & 0.25 & 2.3 & $+\infty$ & 67 & 133 & 457 & 1070 & 391 \\
\hline \#36 & C. & 0.25 & 2.3 & 477 & 71 & 141 & 429 & 1054 & 409 \\
\hline
\end{tabular}

$B$. boring, $C$. cylindrical turning, $F$. face turning 
Table 5 Coefficient values for force models using two-local components, identified from 36 cutting trials

\begin{tabular}{|c|c|c|c|}
\hline \multicolumn{3}{|c|}{ Armarego 2-local component model (8) } & \multirow[t]{2}{*}{ Residual DOF $\left\{f_{v} ; f_{h}\right\} \rightarrow\{34 ; 70$} \\
\hline$k_{v 0}(\mathrm{~N} / \mathrm{mm})$ & $k_{v 1}\left(\mathrm{~N} / \mathrm{mm}^{2}\right)$ & & \\
\hline 57.15 & 1377.31 & & \\
\hline$k_{h 0}(\mathrm{~N} / \mathrm{mm})$ & $k_{h 1}\left(\mathrm{~N} / \mathrm{mm}^{2}\right)$ & & \\
\hline 115.70 & 371.50 & & \\
\hline \multicolumn{3}{|c|}{ 2-local component $R_{c, c}{ }^{o}$ effect model (9) } & Residual DOF $\left\{f_{v} ; f_{h}\right\} \rightarrow\{32 ; 68\}$ \\
\hline$k_{\nu 0}(\mathrm{~N} / \mathrm{mm})$ & $k_{v 1}\left(\mathrm{~N} / \mathrm{mm}^{2}\right)$ & $k_{v 2}(\mathrm{~N} / \mathrm{mm})$ & $k_{v 3}(\mathrm{~mm})$ \\
\hline 58.98 & 1381.84 & -5.89 & -7701.36 \\
\hline$k_{h 0}(\mathrm{~N} / \mathrm{mm})$ & $k_{h 1}\left(\mathrm{~N} / \mathrm{mm}^{2}\right)$ & $k_{h 2}(\mathrm{~N} / \mathrm{mm})$ & $k_{h 3}(\mathrm{~mm})$ \\
\hline-45208.96 & 371.48 & 90652.99 & -0.03 \\
\hline
\end{tabular}

\subsection{Results from the two-local cutting force predictive models}

Although the coefficient values determined, presented in Table 5, are the results of a non-linear and unconstrained mathematical resolution, these values are in accordance with their physical meaning both for the cutting effect and the edge effect (i.e. the cutting forces increase respectively when the uncut chip thickness $h$ or the clearance face contact radius $R_{c, c}{ }^{o}$ is growing). Table 6 presents the relative errors of modelling from the comparison of the measured cutting forces and the modelled cutting forces using models (8) and (9).

The first observation is that Armarego's two-local component model (8) seems to provide a good prediction regarding the average relative errors given in Table 6 and Fig. 16a. Indeed, the two-local component $R_{c, c}{ }^{o}$ effect model (9) presents a slight improvement in the average relative errors for the $F_{p}$ and $F_{f}$ components. However, in this case the average relative error is not a relevant criterion to evaluate the quality of a model. In fact, as observed in Sect. 6, different contact conditions between the flank face and the machined surface generate higher cutting force magnitudes in boring than in face turning,

Table 6 Relative modelling errors provided by the two-local force component models for 36 cutting trials

Relative error on each component (\%)

\begin{tabular}{lll}
\hline$F_{c}$ & $F_{p}$ & $F_{f}$ \\
\hline
\end{tabular}

Armarego 2-local component model (8)

\begin{tabular}{llll} 
Max. & 19 & 21 & 35 \\
Min. & 0 & 1 & 0 \\
Average & 6 & 7 & 11 \\
2-Local component $R_{c, c}{ }^{o}$ effect model (9) & \\
Max. & 21 & 15 & 27 \\
Min. & 0 & 0 & 0 \\
Average & 6 & 5 & 10 \\
\hline
\end{tabular}

and they are also higher than in cylindrical turning. In this study, the experimental design is balanced between the three cutting configurations. Consequently, if a cutting force model is only good at predicting the cutting forces generated in the face turning configuration, the average relative errors, regarding the three turning configurations, will be small because the model averages the $R_{c, c}{ }^{o}$ effect for all these configurations (internal and external). As observed in Fig. 16a, this is the case with the Armarego twolocal component model (8) because it does not take into account the influence of contact conditions on cutting forces. For this reason, the relevant criterion in this case is the maximum relative error, in order to analyse how the cutting forces of the entire experimental design are modelled.

From this point of view, the two-local component $R_{c, c}{ }^{o}$ effect model (9) presents a significant improvement compared to Armarego's two-local component model (8). The maximum relative errors of the $F_{p}$ and $F_{f}$ components are respectively reduced by 6 and $8 \%$. Meanwhile, the maximum relative error of the $F_{c}$ components shows a slight increase of $2 \%$. These results are in accordance with the results observed in Sects. 5 and 6 ; the $F_{p}$ and $F_{f}$ components related to the $f_{h}$ local component are more sensitive to clearance face contact radius variations than the $F_{c}$ components associated with the $f_{v}$ local component.

Finally, the added value of the clearance face contact radius to the cutting force model does exist but is not great enough to be considered as a major breakthrough. That is why the two-local component models have to be enhanced.

\subsection{Development of a three-local component force model}

Inspired by the contributions of Kapoor et al. [40] and Molinari and Moufki [41], the two-local component cutting force models are enhanced by the introduction of a third local component. Even if the tool nose of the round insert is large, the independence of one segment from the 
others may not be a valid hypothesis. The third local cutting force component is representative of chip compression. Indeed, as presented in Fig. 14, this model assumes that the chip has a global flow direction represented by the $\xi_{c, \text { global }}$ angle. Therefore, depending on the orientation of the considered segment, defined as $\theta_{\text {seg,jlocal }}$, the local chip generates an additional force in relation to the angular gap between the global flow direction and the local orientation of the considered segment. This angular gap is expressed as $\eta_{c, j l o c a l}$ and detailed in Eq. (8):

$\eta_{c, j l o c a l}=\xi_{c, \text { global }}-\theta_{\text {seg, }, \text { local }}$

In order to satisfy cutting force equilibrium on the chip, Moufki and Molinari [42] present the variation in the global flow direction with respect to the depth of cut. In the case of a depth of cut lower than the tool nose radius, a typical case when machining with a round insert, the $\xi_{c, g l o b a l}$ angle can be closely approximated by a linear function of the depth of cut. Therefore, based on this observation, a mechanistic model is suggested and expressed in Eq. (9). Additionally, in order to ensure the physical meaning, the global flow direction has to verify a condition expressed in Eq. (10). In this case, the chip flows during the cutting of the material.

$\xi_{c, \text { global }}=k_{o 1}+k_{o 2} \times a_{p}$

$\xi_{c, \text { global }}<90^{\circ}$

Lastly, in order to express the $f_{o}$ local component, a mechanistic model is proposed in Eq. (11). This model defines the $f_{o}$ local component, representing the stress in the chip, as a function of the uncut chip thickness and the $\eta_{c, j l o c a l}$ angle. This is an accurate linear approximation of a more complex formulation proposed by Moufki and Molinari [42].

$f_{o, j}=k_{o 0} \times \eta_{c, j l o c a l} \times h_{j}$
Thanks to the appearance of a third local cutting force component, the equations which define the global cutting forces from the local cutting forces are modified. They are detailed in Eqs. (12) and (13). According to Molinari and Moufki [41], the orientation of the third component is decomposed in the $\left(f_{v}\right.$, $f_{h}, f_{o}$ ) reference frame. However, the contribution of this third component to the global cutting forces is small. Therefore, only the major projection, tangential to the segment, of this component is considered; the others are neglected.

$$
\begin{aligned}
& F_{p}=\sum_{j=1}^{N b_{\text {seg }}} f_{h, j} \times \cos \left(\theta_{j}\right)-f_{o, j} \times \sin \left(\theta_{j}\right) \\
& F_{f}=\sum_{i=1}^{N b_{\text {seg }}} f_{h, j} \times \sin \left(\theta_{j}\right)+f_{o, j} \times \cos \left(\theta_{j}\right)
\end{aligned}
$$

\subsection{Results from the three-local component cutting force predictive models}

Identified coefficients and modelling relative errors are respectively presented in Tables 7 and 8. The identified global flow direction model is physically coherent (i.e. satisfies the Eq. (10) condition), as are the other coefficients used to model the cutting effect and edge effect (i.e. satisfy conditions explained in Sect. 7.3). Moreover, the identified global flow direction model is almost always contained in the chip cross-section area angular range limits defined by $\left\{\theta_{\min }, \theta_{\max }\right\}$ [33], as presented in Fig. 15. This observation confirms the physical meaning of the suggested model.

The first observation is that the consideration of a third local cutting force component leads to a reduction in relative errors. Indeed, between Armarego's two-local component model (8) and Armarego's modified three-local component
Table 7 Values of coefficients for three-local force component

\begin{tabular}{|c|c|c|c|}
\hline \multicolumn{3}{|c|}{ Armarego modified 3-local component model (8) and (12) } & \multirow[t]{2}{*}{ Residual DOF $\left\{f_{v} ;\left\{f_{h} ; f_{o}\right\}\right\} \rightarrow\{34 ; 67\}$} \\
\hline$k_{\nu 0}(\mathrm{~N} / \mathrm{mm})$ & \multicolumn{2}{|l|}{$k_{v 1}\left(\mathrm{~N} / \mathrm{mm}^{2}\right)$} & \\
\hline 57.15 & \multicolumn{2}{|l|}{1377.31} & \\
\hline$k_{h 0}(\mathrm{~N} / \mathrm{mm})$ & \multicolumn{2}{|l|}{$k_{h 1}\left(\mathrm{~N} / \mathrm{mm}^{2}\right)$} & \\
\hline 114.97 & \multicolumn{2}{|l|}{352.97} & \\
\hline$k_{a 0}(\mathrm{~N} / \mathrm{mm})$ & $k_{a 1}\left({ }^{\circ}\right)$ & $k_{a 2}(\% / \mathrm{mm})$ & \\
\hline-2.01 & -0.38 & 0.63 & \\
\hline \multicolumn{3}{|c|}{ 3-Local component $R_{c, c}{ }^{o}$ effect model (9) and (12) } & Residual DOF $\left\{f_{v} ;\left\{f_{h} ; f_{o}\right\}\right\} \rightarrow\{32 ; 65\}$ \\
\hline$k_{\nu 0}(\mathrm{~N} / \mathrm{mm})$ & $k_{v 1}\left(\mathrm{~N} / \mathrm{mm}^{2}\right)$ & $k_{v} 2(\mathrm{~N} / \mathrm{mm})$ & $k_{v 3}(\mathrm{~mm})$ \\
\hline 58.98 & 1381.84 & -5.89 & -7701.36 \\
\hline$k_{h 0}(\mathrm{~N} / \mathrm{mm})$ & $k_{h 1}\left(\mathrm{~N} / \mathrm{mm}^{2}\right)$ & $k_{h 2}(\mathrm{~N} / \mathrm{mm})$ & $k_{h 3}(\mathrm{~mm})$ \\
\hline 42681.43 & 350.25 & -85130.08 & 0.03 \\
\hline$k_{a 0}(\mathrm{~N} / \mathrm{mm})$ & $k_{a 1}\left({ }^{\circ}\right)$ & $k_{a 2}(\% / \mathrm{mm})$ & \\
\hline-1.98 & -0.41 & 0.64 & \\
\hline
\end{tabular}
models for 36 cutting trials 
Table 8 Relative modelling errors shown by the three local force component models for 36 cutting trials

\begin{tabular}{llll}
\hline & \multicolumn{3}{c}{ Relative error on each component $(\%)$} \\
\cline { 2 - 4 } & $F_{c}$ & $F_{p}$ & $F_{f}$ \\
\hline Armarego modified & 3-local component & model (8) and (10) \\
Max. & 19 & 18 & 28 \\
Min. & 0 & 0 & 0 \\
Average & 6 & 7 & 10 \\
3-Local component & $R_{c, c}{ }^{o}$ effect model (9) and (10) & \\
Max. & 21 & 13 & 19 \\
Min. & 0 & 0 & 2 \\
Average & 6 & 4 & 10 \\
\hline
\end{tabular}

model ( 8 and 12), the maximum relative errors of the $F_{p}$ and $F_{f}$ components are respectively reduced by 3 and $7 \%$. The average relative errors are approximately the same.
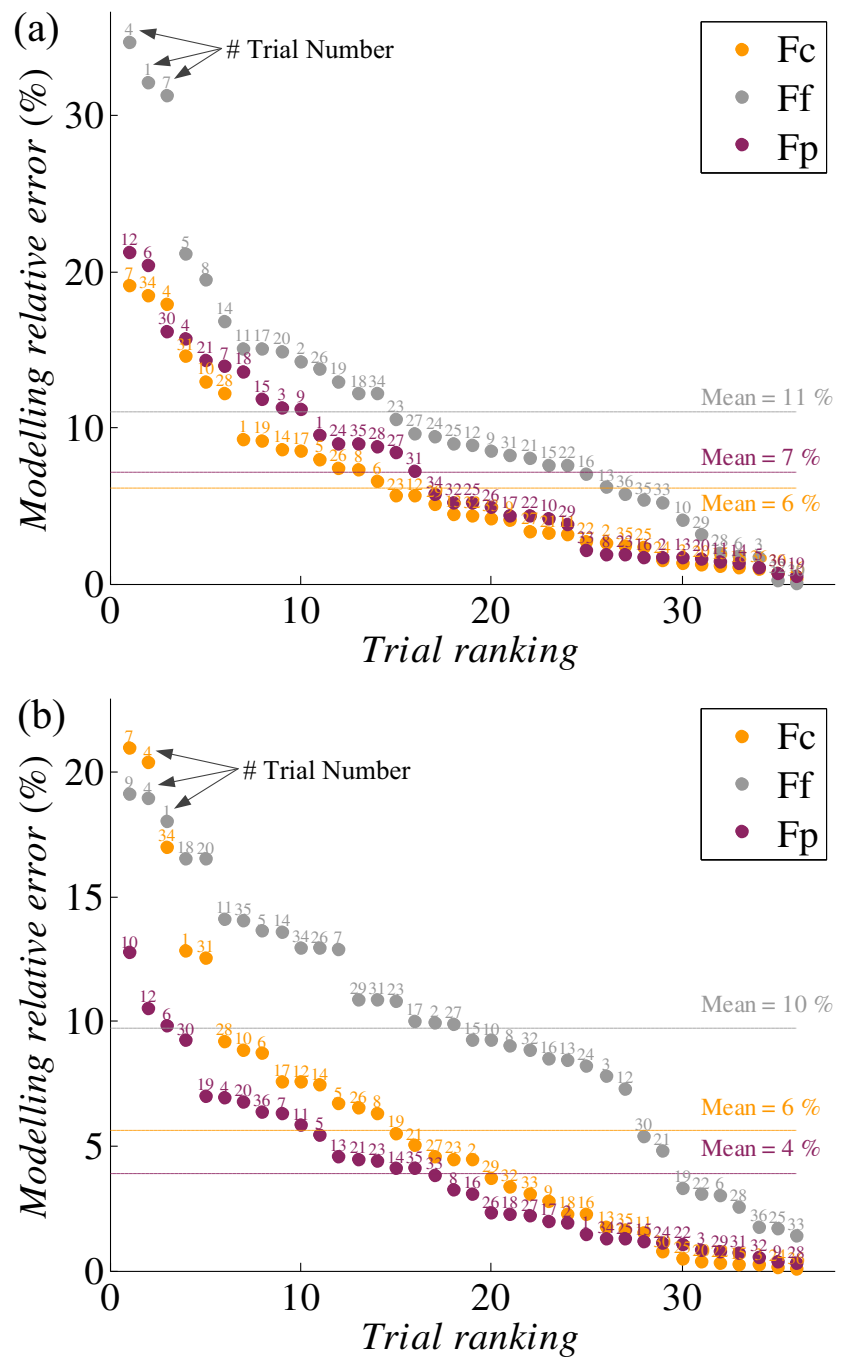

Fig. 16 Relative errors distributions for a model (8) and b model (9 and 13)
The second observation is that adding the clearance face contact radius to the cutting force model is significant. In fact, between Armarego's modified three-local component model (8 and 12) and the three-local component $R_{c, c}{ }^{o}$ effect model (9 and 13), the maximum relative errors of the $F_{p}$ and $F_{f}$ components are respectively reduced by 5 and $9 \%$. These decreases are higher than those provided by adding the third local component. The average relative error for the $F_{p}$ component is even reduced by $3 \%$.

Finally, when the Armarego two-local component model (8) and the three-local component $R_{c, c}{ }^{o}$ effect model (9 and 13) predictions are compared, significant evolutions can be pointed out, as illustrated in Fig. 16. In fact, the maximum relative errors for the $F_{p}$ and $F_{f}$ components decrease respectively by 8 and $16 \%$, while average relative errors for the $F_{p}$ and $F_{f}$ components are respectively reduced by 3 and $1 \%$. Regardless of the global component, the three-local component $R_{c, c}{ }^{o}$ effect model (9 and 13) provides a cutting force model with a maximum relative error of $19 \%$, whereas Armarego's two-local component model (8) presents a maximum relative error of $35 \%$.

\section{Conclusion}

The purpose of this research work is to enhance the prediction of cutting forces in turning operations on Ti6Al4V titanium alloy. Firstly, a new geometrical parameter was defined as the clearance face contact radius $R_{c, c}{ }^{o}$ in cylindrical turning, face turning and boring. In order to improve cutting force modelling, a direct identification methodology was implemented to determine, independently of any other significant parameters, the influence of radius $R_{c, c}{ }^{o}$ and angle $\kappa_{r}$ on cutting forces. Then, based on these conclusions, a new generalised mechanistic model for turning operations was established using an inverse identification methodology. Prediction accuracy was then compared to a commonly used model.

The main conclusions are:

- Variations in the cutting edge lead angle $\kappa_{r}$ have a nonsignificant effect on cutting forces.

- Clearance face contact radius $R_{c, c}{ }^{o}$ and flank wear have coupled effects on cutting forces. The flank wear favours the $R_{c, c}{ }^{o}$ radius effect on cutting forces.

- Variations in radius $R_{c, c}{ }^{o}$ evince a noteworthy increase in cutting forces when the contact radius increases. The effect of radius $R_{c, c}{ }^{o}$ is even more significant when the contact radius is concave.

- Investigations into the physical understanding of the origin of cutting force variations link these variations to a ploughing effect.

- Based on these conclusions, and adopting a mechanistic approach, a new generalised model is proposed by taking 
into account the effects of the uncut chip thickness and the clearance face contact radius for external and internal turning operations.

- The results provided by the proposed model underline an improvement in cutting force prediction by reducing by at least 8 and $16 \%$ the maximum relative errors on the $F_{p}$ and $F_{f}$ components.

In conclusion, a new generalised model is proposed considering contact radius effect and which improves especially the prediction of $F_{f}$ and $F_{p}$ components. This contribution is useful to determine the final geometry of flexible parts after turning. Indeed, those two components are directly linked to their deflections. Therefore, when used as an input data, these enhancements may contribute to advancement in the modelling. For this reason, every gain in cutting force modelling is essential in order to avoid high-cost rejected parts.

Future studies should focus on introducing tool wear as an influential parameter in cutting force models, and simulations have to be made of complex contour turning operations in order to come closer to industrial applications.

\subsection{Nomenclature}

$\begin{array}{ll}a_{p} & \text { Depth of cut } \\ a_{n} & \text { Tool normal clearance angle } \\ b & \text { Width of cut } \\ b_{\text {seg }} & \text { Segment width of discretized edge } \\ \eta_{c} & \text { Local chip flow angular gap } \\ f & \text { Feed per revolution } \\ f_{h} & \text { Normal force on a segment } \\ f_{o} & \text { Tangential force on a segment } \\ f_{v} & \text { Force on a segment in } V_{c} \text { direction } \\ F_{c h i p} & \text { Chip segmentation frequency } \\ F_{c} & \text { Cutting force } \\ F_{f} & \text { Feed force } \\ F_{p} & \text { Radial force } \\ \gamma_{n} & \text { Tool normal rake angle } \\ h & \text { Uncut chip thickness } \\ i & \text { Force component index } \\ j & \text { Edge segment index } \\ \kappa_{r} & \text { Tool cutting edge lead angle } \\ \lambda_{s} & \text { Tool cutting edge inclination angle } \\ L_{c h i p} & \text { Serrated chip length } \\ N b_{\text {seg }} & \text { Total number of segments } \\ \phi_{s e g} & \text { Inclination of chip segment } \\ P_{o} & \text { Tool orthogonal plane } \\ P_{r} & \text { Tool reference plane } \\ r_{\beta} & \text { Edge radius } \\ R_{c, c} o & \text { Contact radius on clearance face } \\ r_{\varepsilon} & \text { Tool nose radius } \\ R_{m} & \text { Machined radius } \\ T_{c h i p} & \text { Serrated chip thickness } \\ & \\ & \end{array}$

$\theta \quad$ Effective cutting edge lead angle

$V_{B} \quad$ Flank wear of the cutting tool

$V_{c} \quad$ Cutting speed

$V_{\text {chip }} \quad$ Chip flow velocity

$V_{f} \quad$ Feed rate

$\xi_{c} \quad$ Global chip flow direction

$\vec{X}_{M} \quad$ Radial axis (machine frame)

$\vec{Y}_{M} \quad$ Tangential axis (machine frame)

$\vec{Z}_{M} \quad$ Axial axis (machine frame)

Acknowledgments The authors would like to thank Vincent Dessoly and Habib Karaouni, from Safran Company, for their technical and material supports given to this study.

\section{References}

1. Ezugwu EO, Wang ZM (1997) Titanium alloys and their machinability—a review. J Mater Process Technol 68:262-274. doi:10. 1016/S0924-0136(96)00030-1

2. Ezugwu EO, Bonney J, Yamane Y (2003) An overview of the machinability of aeroengine alloys. J Mater Process Technol 134: 233-253. doi:10.1016/S0924-0136(02)01042-7

3. Merchant ME (2004) Mechanics of the metal cutting process. I. Orthogonal cutting and a type 2 chip. J Appl Phys 16:267-275. doi:10.1063/1.1707586

4. Astakhov VP (1998) Metal Cutting Mechanics. CRC Press, Boca Raton

5. Sun S, Brandt M, Dargusch MS (2009) Characteristics of cutting forces and chip formation in machining of titanium alloys. Int $\mathrm{J}$ Mach Tools Manuf 49:561-568. doi:10.1016/j.ijmachtools.2009. 02.008

6. Sutter G, List G (2013) Very high speed cutting of Ti-6Al-4V titanium alloy — change in morphology and mechanism of chip formation. Int J Mach Tools Manuf 66:37-43. doi:10.1016/j. ijmachtools.2012.11.004

7. Albrecht P (1960) New developments in the theory of the metalcutting process. Part I: the ploughing process in metal cutting. Trans Am Soc Mech Eng 82:348-358

8. Kienzle O (1952) Die bestimmung von kräften und Leistungen an spanenden Werkzeugen und Werkzeugmaschinen. Z Ver Deut Ing, Hannover, pp 299-305.

9. Günay M, Aslan E, Korkut İ, Șeker U (2004) Investigation of the effect of rake angle on main cutting force. Int J Mach Tools Manuf 44:953-959. doi:10.1016/j.ijmachtools.2004.01.015

10. Armarego EJA, Epp CJ (1970) An investigation of zero helix peripheral up-milling. Int J Mach Tool Des Res 10:273-291. doi:10. 1016/0020-7357(70)90011-9

11. Armarego EJA, Whitfield RC (1985) Computer based modelling of popular machining operations for force and power prediction. Ann CIRP 34:65-69

12. Armarego EJA (2000) The unified-generalised mechanics of cutting approach - a step towards a house of predictive performance models for machining operations. Proc 3rd CIRP Int Workshop Model Mach Oper 4:6-24

13. Reddy RG, Kapoor SG, DeVor RE (2000) A mechanistic force model for contour turning. Trans Am Soc Mech Eng 122:398-405

14. Reddy RG, DeVor RE, Kapoor SG (2001) A mechanistic force model for combined axial-radial contour turning. Int J Mach Tools Manuf 41:1551-1572. doi:10.1016/S0890-6955(01)00030-X 
15. Huang Y, Liang SY (2003) Force modelling in shallow cuts with large negative rake angle and large nose radius tools - application to hard turning. Int J Adv Manuf Technol 22:626-632

16. Ng CK, Melkote SN, Rahman M, Senthil Kumar A (2006) Experimental study of micro- and nano-scale cutting of aluminum 7075-T6. Int J Mach Tools Manuf 46:929-936. doi:10.1016/j. ijmachtools.2005.08.004

17. Wyen C-F, Wegener K (2010) Influence of cutting edge radius on cutting forces in machining titanium. CIRP Ann Manuf Technol 59: 93-96. doi:10.1016/j.cirp.2010.03.056

18. Zorev NN (1966) Metal cutting mechanics. Pergamon Press, Oxford

19. Stevenson R, Stephenson DA (1995) The mechanical behavior of zinc during machining. J Eng Mater Technol 117:172-178. doi:10. $1115 / 1.2804526$

20. Stevenson R (1998) The measurement of parasitic forces in orthogonal cutting. Int J Mach Tools Manuf 38:113-130. doi:10.1016/ S0890-6955(97)00022-9

21. Guo YB, Chou YK (2004) The determination of ploughing force and its influence on material properties in metal cutting. J Mater Process Technol 148:368-375. doi:10.1016/j.jmatprotec.2004.02. 052

22. Popov A, Dugin A (2013) A comparison of experimental estimation methods of the ploughing force in orthogonal cutting. Int $\mathrm{J}$ Mach Tools Manuf 65:37-40. doi:10.1016/j.ijmachtools.2012.09. 003

23. Popov A, Dugin A (2014) Effect of uncut chip thickness on the ploughing force in orthogonal cutting. Int J Adv Manuf Technol 19. doi: 10.1007/s00170-014-6423-1.

24. Waldorf DJ (2006) A simplified model for ploughing forces in turning. J Manuf Process 8:76-82. doi:10.1016/S1526-6125(07) 00005-9

25. Kaymakci M, Kilic ZM, Altintas Y (2012) Unified cutting force model for turning, boring, drilling and milling operations. Int $\mathrm{J}$ Mach Tools Manuf 54-55:34-45. doi:10.1016/j.ijmachtools.2011. 12.008

26. Campocasso S, Costes J-P, Fromentin G et al (2013) Improvement of cutting forces modeling based on oriented cutting tests. Procedia CIRP 8:206-211. doi:10.1016/j.procir.2013.06.090

27. Dorlin T, Fromentin G, Costes J-P (2015) Analysis and modelling of the contact radius effect on the cutting forces in cylindrical and face turning of Ti6Al4 V titanium alloy. Procedia CIRP 31:185190. doi:10.1016/j.procir.2015.03.017

28. Venkatesh VC, Kattan IA, Hoy D et al (1996) An analysis of cutting tools with negative side cutting edge angles. J Mater Process Technol 58:351-361. doi:10.1016/0924-0136(95)02207-4
29. Saglam H, Unsacar F, Yaldiz S (2006) Investigation of the effect of rake angle and approaching angle on main cutting force and tool tip temperature. Int J Mach Tools Manuf 46:132-141. doi:10.1016/j. ijmachtools.2005.05.002

30. Khettabi R, Songmene V, Masounave J (2007) Effect of tool lead angle and chip formation mode on dust emission in dry cutting. $\mathrm{J}$ Mater Process Technol 194:100-109. doi:10.1016/j.jmatprotec. 2007.04.005

31. NF E66-520-4, 1997, Working zones of cutting tools - couple toolmaterial - Part 4: Couple tool-material methodology procedures in turning

32. ISO 3685,1993 , Tool life testing with single point turning tools

33. Campocasso S, Costes J-P, Fromentin G, et al. A generalised geometrical model of turning operations for cutting force modelling using edge discretisation. Appl Math Model. doi: 10.1016/j.apm. $2015.02 .008<$

34. ISO 3002-1, 1993, Basic quantities in cutting and grinding

35. Smithey DW, Kapoor SG, DeVor RE (2000) A worn tool force model for three-dimensional cutting operations. Int $\mathrm{J}$ Mach Tools Manuf 40:1929-1950. doi:10.1016/S0890-6955(00)00017-1

36. Wang J, Huang CZ, Song WG (2003) The effect of tool flank wear on the orthogonal cutting process and its practical implications. J Mater Process Technol 142:338-346. doi:10.1016/S0924-0136(03) 00604-6

37. Brown RH, Armarego EJA (1964) Oblique machining with a single cutting edge. Int J Mach Tool Des Res 4:9-25. doi:10.1016/00207357(64)90006-X

38. Waldorf DJ, DeVor RE, Kapoor SG (1999) An evaluation of ploughing models for orthogonal machining. J Manuf Sci Eng 121:550-558. doi:10.1115/1.2833050

39. Lin B, Wang L, Guo Y, Yao J (2015) Modeling of cutting forces in end milling based on oblique cutting analysis. Int J Adv Manuf Technol 1-10. doi: 10.1007/s00170-015-7724-8

40. Kapoor SG, DeVor RE, Zhu R et al (1998) Development of mechanistic models for the prediction of machining performance: model building methodology. Mach Sci Technol 2:213-238. doi:10.1080/ 10940349808945669

41. Molinari A, Moufki A (2005) A new thermomechanical model of cutting applied to turning operations. Part I. Theory. Int J Mach Tools Manuf 45:166-180. doi:10.1016/j.ijmachtools.2004.07.004

42. Moufki A, Molinari A (2005) A new thermomechanical model of cutting applied to turning operations. Part II. Parametric study. Int J Mach Tools Manuf 45:181-193. doi:10.1016/j.ijmachtools.2004. 07.005 